\title{
əFog and Low-Level Stratus in Coupled Ocean-Atmosphere Simulations of the Northern California Current System Upwelling Season
}

\author{
R. M. Samelson, ${ }^{a}$ S. P. De Szoeke, ${ }^{a}$ E. D. Skyllingstad, ${ }^{a}$ P. L. Barbour,${ }^{a}$ And S. M. Durski ${ }^{a}$ \\ ${ }^{a}$ College of Earth, Ocean, and Atmospheric Sciences, Oregon State University, Corvallis, Oregon
}

(Manuscript received 21 May 2020, in final form 19 February 2021)

\begin{abstract}
Fog and low-level stratus during April-September 2009 are examined in a set of coupled ocean-atmosphere numerical simulations of the northern California Current System (CCS). The model configurations differ only in the choice of planetary boundary layer (PBL) parameterization scheme and, in one case, surface flux scheme. The results suggest that fog formation in this region primarily occurs through condensation at the surface induced locally by surface cooling, when moist offshore air is advected over cold upwelled waters and the shallow coastal marine PBL is further stabilized by warm, dry, continental air that extends offshore above the PBL inversion. These results are consistent with some but not all prior hypotheses for fog formation in the CCS region. Fog formation by downward growth of a preexisting stratus layer is also found in the simulations, but dominates only in those simulations with PBL schemes that produce an extensive and evidently unphysical stratus layer at $200 \mathrm{~m}$ height, which serves as the source for the downward growth. The stronger fog response in later summer months arises from seasonal warming of offshore SST, which increases the moisture content and temperature of the upstream air mass, while cool coastal SSTs are maintained by upwelling. On synoptic time scales, a similar influence of fog response on upstream conditions is found but controlled instead by changes in wind direction. These results suggest that the critical factors determining the evolution of the coastal fog regime in a warming climate are likely the temperature of upwelling source waters and the offshore flow of continental air.
\end{abstract}

KEYWORDS: Air-sea interaction; Cloud cover; Coastal meteorology; Mesoscale models; Numerical weather prediction/forecasting; Ocean models

\section{Introduction}

The U.S. West Coast is well known for its frequent coastal marine fogs, particularly during the summer months and in the region extending from Point Conception near $35^{\circ} \mathrm{N}$ northward to the Strait of Juan de Fuca near $47^{\circ} \mathrm{N}$. The difficulties posed to navigation by the frequent foggy conditions were one of the conditions cited by Jones (1918) as reasons to undertake immediate surveys of the "neglected" West Coast waters; Jones (1918) noted that at that time it was "by no means uncommon for a vessel to be compelled to make the entire run from the Strait of Juan de Fuca or the Columbia River to San Francisco without obtaining a sight of land." More recently, West Coast marine fog has been identified as a critical element of the habitat of the iconic coast redwood (Sequoia sempervirens), one of the largest, longest-lived, and oldest extant tree species, and the possibility that changes in the coastal fog climate could affect redwood species health and survival has been recognized (Johnstone and Dawson 2010). The coast redwood habitat extends to altitudes of approximately $400 \mathrm{~m}$, and consequently both fog and low-level coastal stratus are of interest in this context.

In general, the modeling and prediction of marine fog remains a continuing challenge more than half a century after

\footnotetext{
D Denotes content that is immediately available upon publication as open access.
}

Corresponding author: R. M. Samelson, roger.samelson@ oregonstate.edu the genesis of operational numerical weather prediction (Koračin et al. 2014). Fog formation through condensation is a criticalpoint phase-change process that is sensitive to numerous factors, each of which is itself difficult to predict with quantitative accuracy. In addition, the proximity of the air-sea interface introduces dependence of fog on air-sea fluxes, turbulence, and other boundary layer processes that remain only partly understood and must be represented in models by parameterizations that are necessarily crude and incomplete. Progress requires improved understanding both of the dependence of fog formation on these various processes and of the dynamics and mechanisms of the processes themselves.

The approach taken here is to analyze fog and low-level stratus distributions and formation processes in a suite of coupled ocean-atmosphere model simulations of the northern California Current System (CCS). The coupled modeling system used for these simulations combines regional ocean and mesoscale atmosphere components that have a long heritage of development and validation against observations, both in a general sense across the research and operational communities and for the specific northern CCS region that is the focus of this study. This history is briefly summarized in section 2 , which also contains a detailed description of the modeling configuration. Based on this history, it can be asserted with confidence that many important aspects and features of the regional ocean circulation and coastal meteorological regime during the upwelling season are represented with meaningful physical veracity in these coupled simulations. This extends to coupled air-sea boundary layer phenomena such as SST-stress coupling, which has been analyzed in this same suite of simulations and compared in detail with satellite remote sensing observations 

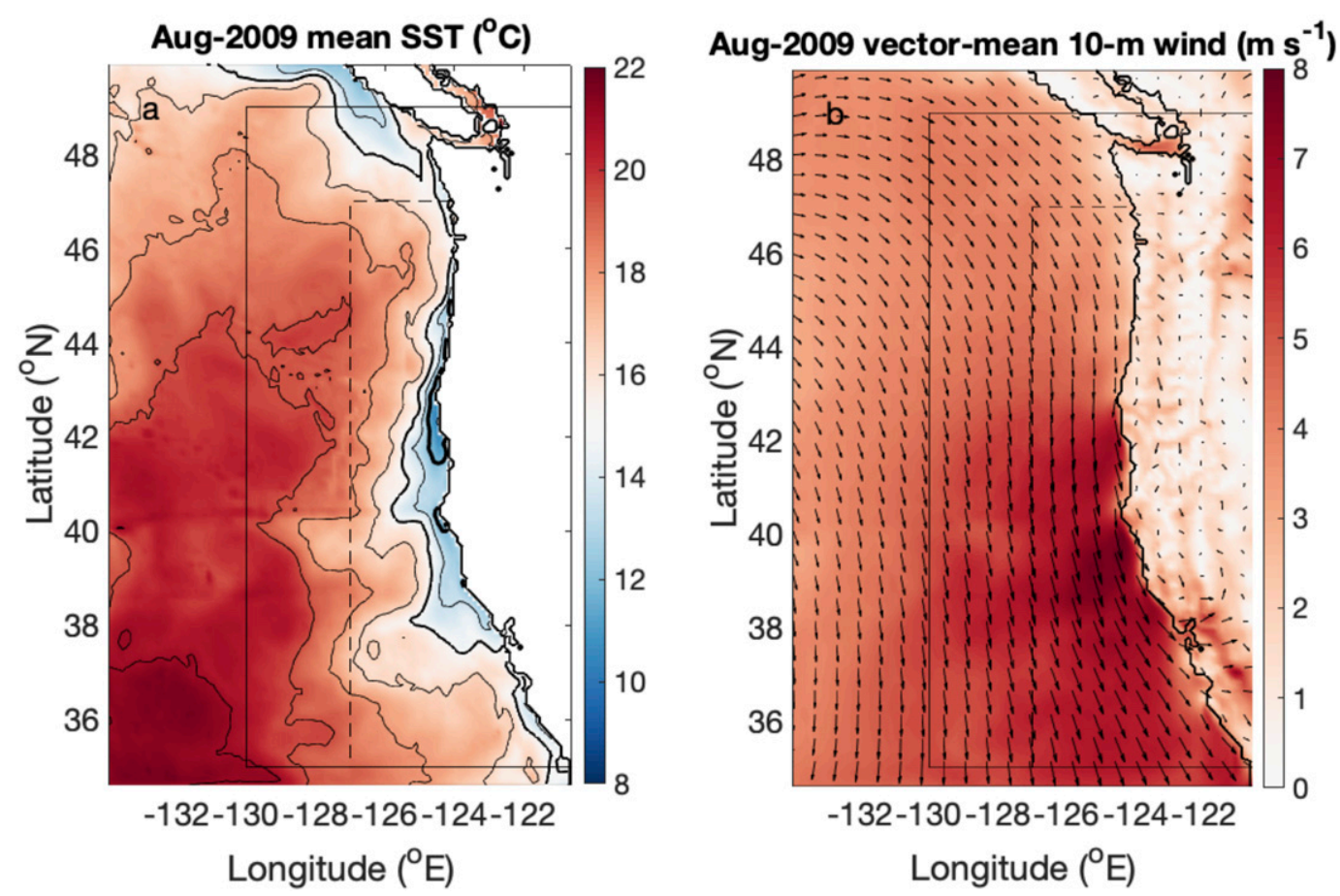

FIG. 1. Ensemble-mean August 2009 (a) sea surface temperature $\left({ }^{\circ} \mathrm{C}\right.$; shading and contours with $1.5^{\circ} \mathrm{C}$ contour intervals; thick lines: $12^{\circ}$ and $15^{\circ} \mathrm{C}$ contours) and (b) $10 \mathrm{~m}$ wind magnitude $\left(\mathrm{m} \mathrm{s}^{-1}\right)$ and vectors, vs longitude $\left({ }^{\circ} \mathrm{E}\right)$ and latitude $\left({ }^{\circ} \mathrm{N}\right)$. Vectors are shown at every fifth model grid point in longitude and in latitude. The full domain of the coupled ocean and inner-nest atmospheric models is shown. The subregion shown in Fig. 2 and other similar figures (black solid line) and the smaller coastal subregion used to compute the frequency statistics in Fig. 5 (black dashed line) are also indicated. The ensemble mean is computed over all six simulations.

by Samelson et al. (2020). It is thus natural to inquire what the fog and low-level stratus distributions in these simulations are and how they are controlled physically. The existence of this suite of simulations offers the opportunity for a novel, ensemble-based, season-long analysis that is more extensive and systematic in spatial and temporal coverage than any previous modeling study of West Coast fog dynamics.

The results of that analysis are described here. The suite of model simulations is a subset of those described and analyzed by Samelson et al. (2020), and includes simulations using five different parameterizations of turbulence in the atmospheric planetary boundary layer (PBL), which can be anticipated to give differing representations of the boundary layer dynamics involved in marine fog formation. One objective was to identify features of the model fog and low-level stratus responses that were relatively independent of PBL parameterization and consequently might be inferred to be robustly represented in the simulations. A second objective was to place these robust results in the context of previous, related work on the West Coast fog and low-level stratus regime (e.g., McEwen 1912; Palmer 1917; Byers 1930; Anderson 1931; Petterssen 1938; Leipper 1948, 1994; Simon 1977; Pilié et al. 1979; Klein and Hartmann 1993; Filonczuk et al. 1995; Koračin et al. 2001, 2005a,b; O'Brien et al. 2013; Koračin et al. 2014; Clemesha et al. 2016, 2017; Dye et al. 2020) and thereby to derive and refine hypotheses regarding the dominant physical mechanisms that control this regime, which could be tested by future observational studies. A third, more technical objective was to identify features of the model fog and low-level stratus responses that depended on the different PBL parameterizations and, to the extent possible based on existing observations, to assess their relative performance of those schemes in reproducing observed fog and low-level stratus characteristics. A fourth objective is to determine the implications of the results for the problem of anticipating potential future changes in the coastal fog climate along the U.S. West Coast in the context of its role in the coast redwood ecosystem.

\section{Methods}

\section{a. Model configuration}

The ocean-atmosphere simulations of the northern CCS region (Fig. 1) were computed using a coupled Weather Research and Forecasting (WRF) Model (Skamarock et al. 2008)-Regional Ocean Modeling System (ROMS; Shchepetkin and McWilliams 2005) numerical model configuration based on the Coupled Ocean-Atmosphere Wave Sediment-Transport (COAWST; Warner et al. 2010) system. Modifications to the standard COAWST distribution were made to allow bilinear interpolation of the fields exchanged between the ocean and atmosphere models and to include surface current coupling in an additional subset of simulations, not considered in this analysis. The horizontal grid resolutions were approximately $2 \mathrm{~km}$ for 
the ROMS domain and approximately $12 \mathrm{~km}$ for the coupled, inner-nest WRF domain. The vertical WRF grid had 51 mass and horizontal velocity levels, with 17 levels below $1500 \mathrm{~m}, 7$ levels below $200 \mathrm{~m}$, and lowest level at $10 \mathrm{~m}$ above the sea surface (see Fig. A1 of Samelson et al. 2020). The 7 March 2009 ocean field from the Durski et al. (2015) ocean-only ROMS simulation initiated in October 2008 was used to initialize the ocean component of the coupled model. The coupled model was then integrated for the period 7 March-15 October 2009. A more complete summary of the model configuration is available in Samelson et al. (2020). The primary analysis period was the four summer upwelling months June-September 2009 but some results for April 2009 are also discussed.

The ocean component of the coupled model was essentially identical to the ocean-only northern CCS model developed and analyzed by Durski et al. (2015), who found that their model solution compared favorably to an extensive collection of in situ and remote sensing observations of regional ocean surface and interior properties. Development of that model benefited directly from many prior modeling studies of the northern CCS with systematic observational validation, including Springer et al. (2009) and Oke et al. (2002) as well as other related references therein. An extension of this model, on a larger domain with a coarser horizontal grid, is the basis of the existing National Oceanic and Atmospheric Administration West Coast Operational Forecast System (Kurapov et al. 2017a,b) The implementation of the atmospheric component, based on the community-standard WRF Model, was developed as an extension of previous regional mesoscale atmospheric model studies of the northern CCS region that likewise involved systematic observational validation, including Perlin et al. (2004), Samelson et al. (2002) and Bielli et al. (2002), as well as the related WRF-based study by Perlin et al. (2014) of air-sea interaction in the Agulhas Current Region. The WRF Model also formed the basis of the operational National Centers for Environmental Prediction (NCEP) North American Mesoscale (NAM) atmospheric forecast system prior to the adoption of the current nonhydrostatic B-grid model, and strongly influenced many aspects of the technical development of the latter (Janjic and Gall 2012). The PBL parameterizations used (see below) were all standard WRF options that have been used in a wide variety of previous research and operational simulations, including the MYJ scheme used in both generations of the operational NCEP NAM models. The same set of coupled-model simulations analyzed here were previously analyzed and compared in detail with observations by Samelson et al. (2020). Consequently, additional verification of the basic aspects and features of these coupled-model simulations was not undertaken for this study, which focuses specifically on the model fog and low-level stratus responses, both of which, in turn, remain in general poorly constrained for the northern CCS region by existing observational datasets.

A total of six simulations, using five different PBL parameterizations, were analyzed. These five schemes were the same set considered by Samelson et al. (2020), comprising a subset of those previously considered by Perlin et al. (2014): YSU (Hong et al. 2006), MYJ (Janjić 1994, 2001), MYNN2 (Nakanishi and Niino 2004, 2006, 2009; Olson et al. 2019), UW (Bretherton and Park 2009), and GBM (Grenier and Bretherton 2001; Bretherton et al. 2004), corresponding, respectively, to WRF boundary layer physics parameter ipbl_physics $=\{1,2,5,9,12\}$. A summary of the basic characteristics of these PBL schemes is available in Perlin et al. (2014) and Samelson et al. (2020) and is not repeated here. The MYJ simulation was conducted using the WRF-standard MYJ Monin-Obukhov (Janjić Eta) surface layer scheme (WRF surface-layer physics parameter sf_sfclay_physics = 2). A second simulation, denoted MYJ1, was then conducted using a modified MYJ scheme and the revised MM5 Monin-Obukhov scheme (sf_sfclay_physics $=1$ ), which was used for all of the other four simulations, so that only the PBL schemes differ within the set of five that excludes the MYJ simulation. All six of these simulations were coupled only through the sea surface temperature field. An additional set of simulations that also included surface current coupling was discussed by Samelson et al. (2020) but is not included in the fog and low-stratus analysis, as preliminary assessments revealed that the systematic effects, if any, of the surface current coupling on the fog and low-stratus responses in these simulations were negligible compared to the differences between the results for different PBL schemes. The other WRF physics options used in these simulations are recorded in the appendix.

Fog is distinguished from low-level stratus by its occurrence immediately adjacent to the underlying surface, and is defined for this analysis in terms of surface cloud liquid water, represented and quantified in the simulations as the value of the cloud liquid water mixing ratio $r_{c}$ at the lowest model level (10 m height), where $r_{c}$ (WRF variable QCLOUD) is the ratio of cloud liquid water mass to dry air mass in a unit volume. Low-level stratus is defined for this analysis as the mean cloud liquid water mixing ratio $r_{c}$ from the surface $(10 \mathrm{~m})$ to a nominal height of $400 \mathrm{~m}$, where the latter is specified here as local surface pressure minus $50 \mathrm{hPa}$ and corresponds approximately to $960 \mathrm{hPa}$ in the spatiotemporal means. Values of $r_{c}$ and the water vapor mixing ratio $r_{v}$ are reported in $\mathrm{g} \mathrm{kg}^{-1}$, i.e., dimensionless units of $10^{3}$ times the corresponding mass ratio.

An alternative view of the fog and low-level stratus variability that is more intuitively accessible than the mixing ratio $r_{c}$ is provided by the estimated visibility distance $x_{\text {vis }}$ associated with a given value of $r_{c}$. Following Kunkel (1984) and Stoelinga and Warner (1999), this distance is computed here as $x_{\mathrm{vis}}=\ln 50 / \beta$, where the empirical extinction coefficient $\beta=144.7\left(\rho_{a} r_{c}\right)^{0.88} \mathrm{~km}^{-1}$ for cloud liquid water mass concentration $\rho_{a} r_{c}$ in units of grams per cubic meter. A nominal value $\rho_{a}=1.2 \times 10^{3} \mathrm{~g} \mathrm{~m}^{3}$ is used for the dry-air density, and a minimum value $r_{c}=10^{-9} \mathrm{~g} \mathrm{~kg}^{-1}$ is imposed to avoid the singularity in $x_{\mathrm{vis}}$ at $r_{c}=0$. Typical values of $x_{\mathrm{vis}}$ range from $10 \mathrm{~km}$ or more for nominal clear-sky conditions (visibility to the horizon) to $100 \mathrm{~m}$ or less for thick fog. An alternate visibility distance formulation has been suggested by Gultepe et al. (2006) but could not be computed because of its dependence on a cloud droplet number concentration parameter that is not available for the microphysics scheme used in these simulations (see the appendix).

\section{b. Airport observations}

We compare the distribution of cloud-base height and fog fraction in the model to automated surface observing system (ASOS) reports from August 2009. The observations were 
made by ceilometers and surface optical scattering sensors at Crescent City (latitude $41.8^{\circ} \mathrm{N}, 17 \mathrm{~m}$ above sea level, approximately $1 \mathrm{~km}$ from ocean coast), Arcata $\left(41.0^{\circ} \mathrm{N}, 66 \mathrm{~m}, 1 \mathrm{~km}\right)$, San Francisco $\left(37.6^{\circ} \mathrm{N}, 3 \mathrm{~m}, 10 \mathrm{~km}\right)$, Monterey $\left(36.6^{\circ} \mathrm{N}, 77 \mathrm{~m}\right.$, $3 \mathrm{~km})$, Lompoc $\left(34.7^{\circ} \mathrm{N}, 27 \mathrm{~m}, 13 \mathrm{~km}\right)$, and Santa Barbara $\left(34.4^{\circ} \mathrm{N}, 3 \mathrm{~m}, 1 \mathrm{~km}\right)$ coastal airports. Observed cloud base is detected by automated ceilometer cloud-base algorithm. The observed fraction of mist or fog (visibility $<7 \mathrm{mi}$ ) at the surface is compared to the cloud fraction (mixing ratio $\geq 10^{-4} \mathrm{~kg} \mathrm{~kg}^{-1}$ ) of the lowest model grid. Cloud-base-height frequencies are counted on $30 \mathrm{~m}$ ceilometer range gates above the ground surface, and on (unevenly spaced) model layers above sea level on marine model grid locations nearest to each airport.

\section{Results}

\section{a. Coastal ocean-atmosphere summer circulation}

The coupled numerical simulations reproduce the characteristic features of the summertime upwelling circulation in the northern California Current System: southward wind stress that drives offshore Ekman transport and upwelling of cold ocean water near the coast (Fig. 1). The southward wind stress arises from the pressure gradient between the east Pacific high and the continental thermal low, and is modulated by interaction with the coastal orography, which produces distinctive intensifications of stress and upwelling south of Capes Blanco, near $43^{\circ} \mathrm{N}$, and Mendocino, near $40.5^{\circ} \mathrm{N}$ (Perlin et al. 2004). Instabilities of the coastal ocean currents cause significant variability in the mesoscale surface ocean structure between the individual simulations, with sea surface temperatures (SST) at offshore locations often reaching colder values in the individual simulations than in the ensemble mean. These differences in simulated SST structure increase with elapsed time from the common initialization on 7 March 2009, and induce corresponding differences in the coupled coastal fog and low-level stratus responses. However, SST is not the only factor controlling variability in coastal fog formation in these simulations.

\section{b. Monthly mean fog}

The coupled-model monthly mean distributions of fog (i.e., surface $r_{c}>0$; see section 2a) are dependent on position and PBL scheme. The dependence on PBL scheme is relatively consistent between months and so can be illustrated by reference to the August means (Fig. 2). The fog distributions for the simulations with the YSU and MYJ schemes show significant differences from those for the simulations with the GBM, UW, and MYNN2 schemes. The MYJ simulation, which uses the MYJ scheme with the MYJ-standard surface-layer scheme, has the least fog. Those with the most fog are the YSU and, perhaps surprisingly, MYJ1 simulations, where the latter again uses the MYJ PBL scheme but substitutes the surface-layer flux scheme used in the other simulations in place of the MYJ standard surface-layer scheme. Qualitatively similar mean fog patterns are found during all summer months, with comparable values of $r_{c}$ in July and September, and smaller values in June. In the August means for the UW simulation especially, and also for
MYNN2, GBM, and YSU, the largest surface $r_{c}$ values are strongly localized over the regions with $\mathrm{SST}<15^{\circ} \mathrm{C}$, while those for MYJ and MYJ1 are more broadly distributed over the region with $\mathrm{SST}<18^{\circ} \mathrm{C}$. The latter isotherm also confines almost all of the $r_{c}>0.05 \mathrm{~g} \mathrm{~kg}^{-1}$ values for all except MYJ1. Similar localization of $r_{c}$ over the cool-SST regions is found during the other summer months.

Fog presence may also be quantified in terms of the frequency or probability of low visibility at each point. The distributions of high monthly mean probability of low surface visibility, defined as $x_{\mathrm{vis}}<1 \mathrm{~km}$ (Fig. 2, bottom panels), are qualitatively similar to the mean surface $r_{c}$ distributions, with large mean $r_{c}$ corresponding to high probability of low visibility, and small $r_{c}$ to low probability of low visibility. For MYNN2, GBM, and UW, the August-mean probability of $x_{\text {vis }}<1 \mathrm{~km}$ approaches $50 \%$ in the regions with SST $<15^{\circ} \mathrm{C}$. For MYJ, this probability is generally less than $25 \% \mathrm{ev}-$ erywhere, and generally largest more uniformly across the broader coastal region with SST $<18^{\circ} \mathrm{C}$, while for YSU and MYJ1 this probability generally exceeds $50 \%$ over that broader region, and exceeds $25 \%$ even over much of the region farther offshore with $\mathrm{SST}>18^{\circ} \mathrm{C}$.

The dominant SST-related coastal fog structures in the northern CCS upwelling region are generally contained within a coastal subregion (Fig. 1) that is bounded offshore by $127^{\circ} \mathrm{W}$ and to the south and north by $35^{\circ}$ and $47^{\circ} \mathrm{N}$, respectively. Monthly mean probability distribution functions of 3-hourly gridpoint values of surface $r_{c}$ for this coastal subregion show a seasonal modulation, with the probability of large $r_{c}$ greatest in July and August, least in April, and intermediate in May, June, and September (Fig. 3). The broader areal coverage of large $r_{c}$ for YSU and MYJ1 is reflected in systematically higher probabilities of $r_{c}>0$ for YSU and MYJ1 than for the other simulations. Consistent with the maps of mean August surface $r_{c}$ and low-visibility fraction (Fig. 2), the MYJ $r_{c}$ distributions are generally smaller than MYNN2, GBM, and UW for $r_{c}$ between 0.2 and $0.5 \mathrm{~g} \mathrm{~kg}^{-1}$. Except during April and June, for which the distributions have a more linear structure, the probability distributions all tend to be roughly constant for $r_{c}$ values between 0.05 and $0.3 \mathrm{~g} \mathrm{~kg}^{-1}$ and then decline rapidly for larger $r_{c}$. In all months and for all simulations, with the exceptions of YSU and MYJ1 in July and August, the fog-free value $r_{c}=0$ is more probable than $r_{c}>0$ in the coastal subregion overall.

The combination of the roughly uniform or linearly decreasing probabilities in the range $0.05<r_{c}<0.3 \mathrm{~g} \mathrm{~kg}^{-1}$, the high probability of fog-free $\left(r_{c}=0\right)$ conditions, and the inversepower-law dependence of $x_{\text {vis }}$ on $r_{c}$ results in a bimodal structure of the corresponding monthly mean probability distribution functions of 3-hourly surface $x_{\text {vis }}$ in the coastal subregion. Most values correspond either to very low visibility, $30<x_{\text {vis }}<300 \mathrm{~m}$, or to very high visibility, $x_{\mathrm{vis}}>10 \mathrm{~km}$, where the latter represents clear-sky conditions and is dominated by conditions with $x_{\mathrm{vis}}>$ $100 \mathrm{~km}$. The peak value of the low-visibility lobe of the distribution function generally falls between 50 and $75 \mathrm{~m}$ (Fig. 4). The magnitude of the low-visibility peak varies by an order of magnitude between extremes in the full ensemble of months and simulations, but all of the low-visibility lobes are nearly 
Aug-2009 mean $r_{c}(g / k g)$ for surface level
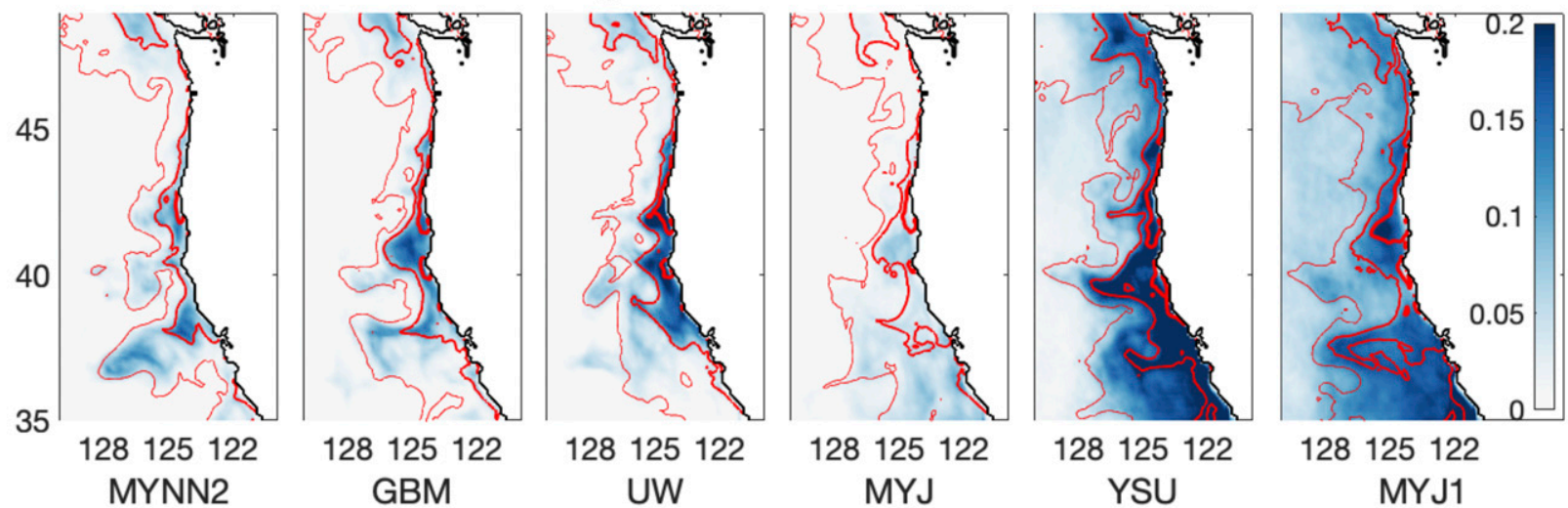

Aug-2009 mean fraction $x_{\text {vis }}$
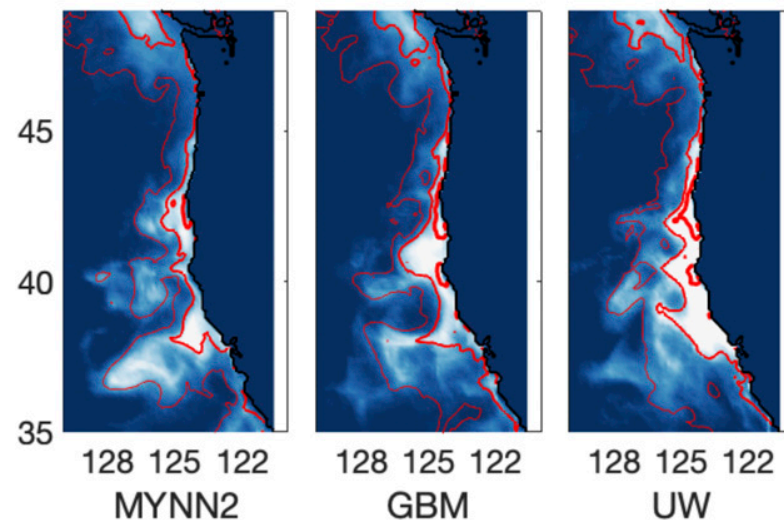

$(\mathbf{k m})<1 \mathrm{~km}$

FIG. 2. August 2009 surface (top) mean cloud liquid water mixing ratio $r_{c}\left(\mathrm{~g} \mathrm{~kg}^{-1}\right)$ and (bottom) fraction of 3-hourly output-field values with $x_{\text {vis }}<1 \mathrm{~km}$, for each of the simulations. The $12^{\circ}$ (thick), $15^{\circ}$, and $18^{\circ} \mathrm{C}$ (thin) SST contours (red) are also shown, and each panel is labeled by the WRF PBL scheme used in the corresponding simulation.

self-similar when normalized by their peak values, reflecting the approximately constant $r_{c}$ distributions near $r_{c} \approx$ $0.22 \mathrm{~g} \mathrm{~kg}^{-1}$, for which $x_{\text {vis }} \approx 100 \mathrm{~m}$. For each month, the relative magnitudes of these peak values for the different PBL simulations can be inferred from the relative levels of the corresponding $r_{c}$ distributions (Fig. 3) and generally follow the pattern of relative values for August (Fig. 4).

In the coastal subregion (Fig. 1), the instantaneous area with visibility distance less than $1 \mathrm{~km}$ varies on diurnal, synoptic, and seasonal time scales (Fig. 5). Large diurnal fluctuations in this measure of fog extent are evident especially for the YSU, MYJ1, and MYJ simulations. For these simulations, the area frequently exceeds $2 \times 10^{5} \mathrm{~km}^{2}$, approaching complete coverage of the coastal subregion. The stronger diurnal fluctuations in $x_{\mathrm{vis}}$ for YSU, MYJ, and MYJ1 relative to MYNN2, GBM, and UW are evident in distributions of the probability of low surface visibility, $x_{\text {vis }}<1 \mathrm{~km}$, computed separately at the daily times of maximum and minimum insolation (Fig. 6). These show, for example, that at the time of maximum insolation, fog is rarely present anywhere for MYJ and is generally restricted to regions with $\mathrm{SST}<15^{\circ} \mathrm{C}$ for YSU, but is only modestly reduced relative to the time of minimum insolation for MYNN2. The GBM and UW diurnal variability is similar to that for MYNN2, while that for MYJ1 is similar to that for YSU.

\section{c. Monthly mean low-level stratus}

Like the mean fog distributions, the monthly mean distributions of low-level stratus (surface to $400 \mathrm{~m}$ mean $r_{c}$ ) in these simulations are strongly dependent on position and on PBL scheme (Fig. 7). For the MYNN2, GBM, and UW simulations, large low-level cloud water values (mean $r_{c}>0.03 \mathrm{~g} \mathrm{~kg}^{-1}$ ) are confined within several hundred $\mathrm{km}$ of the coast, while for the MYJ and YSU schemes, large values extend over most of the ocean domain. Generally similar patterns are again found for this mean low-level stratus during the other summer months. With the exception of MYJ, the relative intensities of fog and low-level stratus are similar for each simulation, with YSU and MYJ1 producing the most fog and low-level stratus and the MYNN2 producing the least of both among all but MYJ. In contrast, the MYJ simulation produces extensive low-level stratus, comparable to that of YSU, but produces the least fog of all.

The extensive offshore low-level stratus in the MYJ, YSU, and MYJ1 simulations is confined to a shallow layer just below 


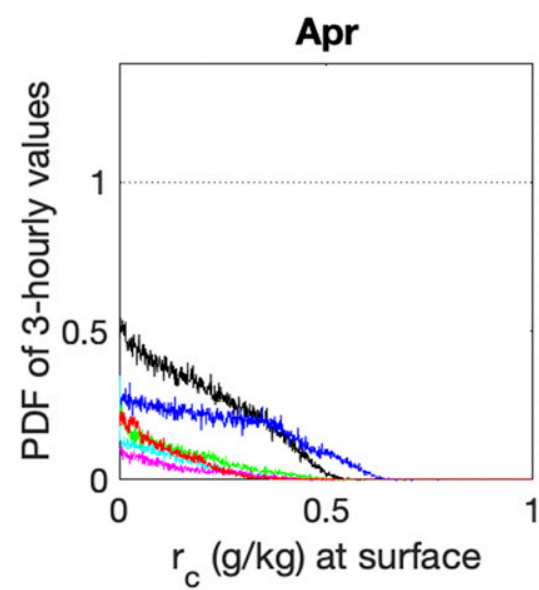

Jul

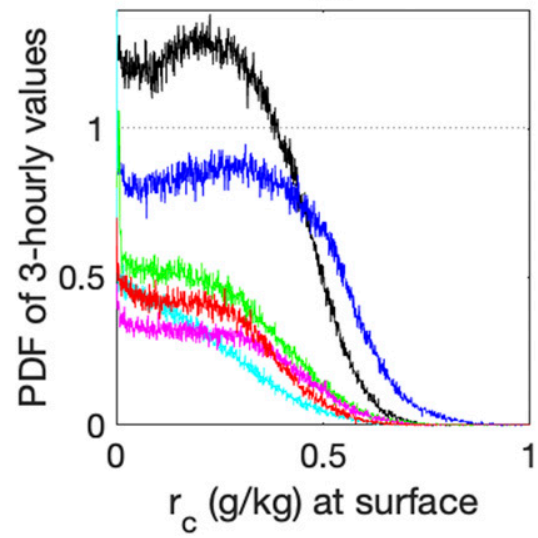

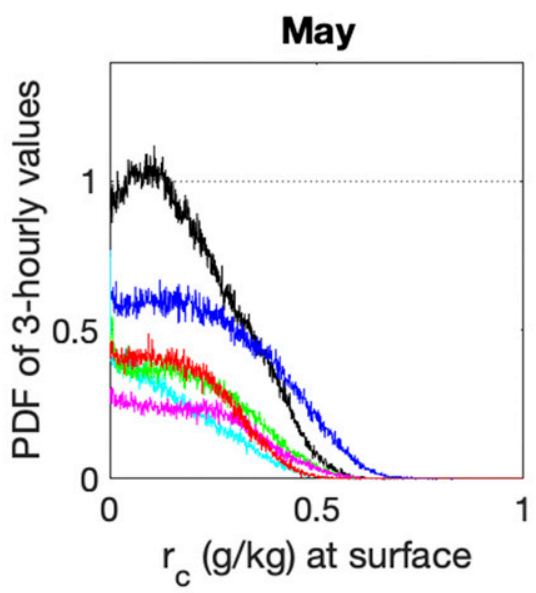

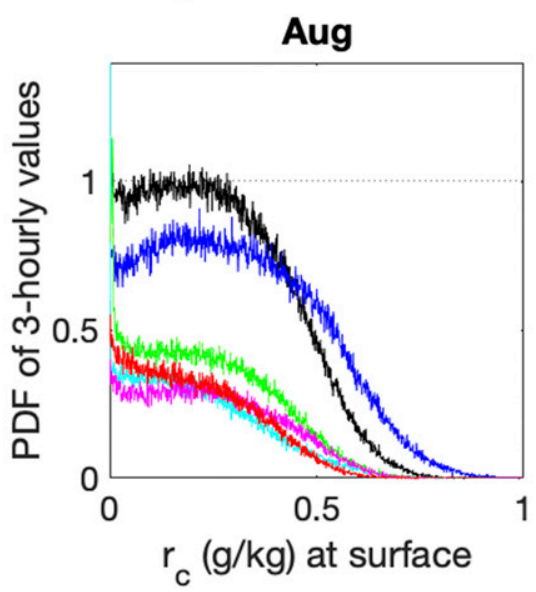

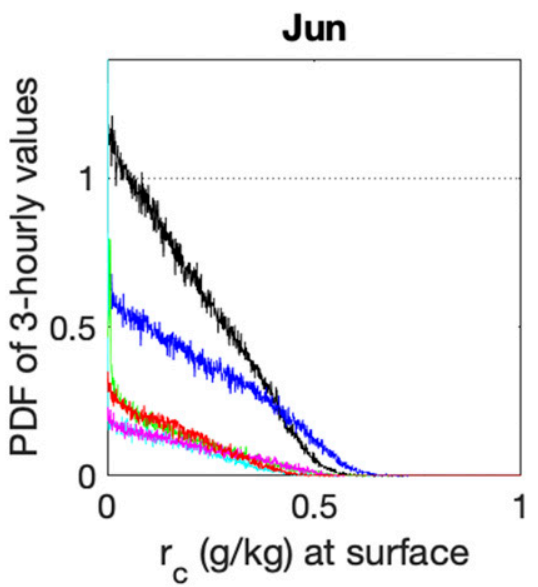

Sep

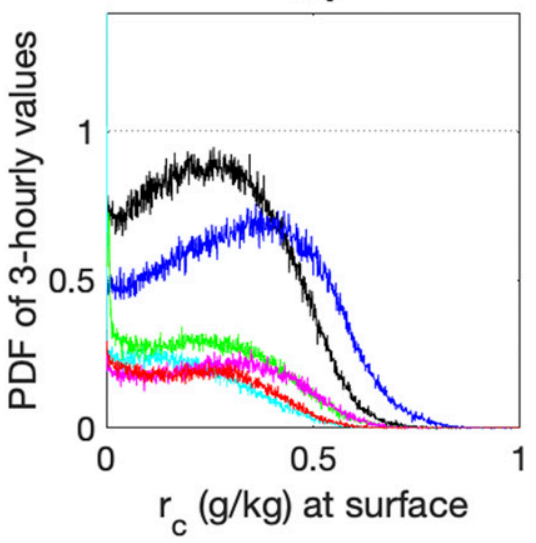

FIG. 3. Monthly probability distribution functions of $r_{c}\left(\mathrm{~g} \mathrm{~kg}^{-1}\right)$ from 3-hourly output-field values in the coastal frequency-statistics subregion (Fig. 1) for MYNN2 (red), GBM (magenta), UW (green), MYJ (cyan), YSU (blue), and MYJ1 (black). The corresponding cumulative probabilities of $r_{c}>0$ are the total areas under each curve. The large number of $r_{c}=0$ values corresponding to the cumulative probability of $r_{c}=0$ are represented by the complementary area relative to a unit area, such as that beneath the indicated unit PDF value (dotted line), but are not shown directly.

the base of the potential temperature gradient capping the marine atmospheric boundary layer, at a nearly constant fixed height between 100 and $300 \mathrm{~m}$ (near $1000 \mathrm{hPa}$ in Fig. 8). In contrast, mean $r_{c}$ west of $127^{\circ} \mathrm{W}$ for the GBM, UW, and MYNN2 simulations is nearly zero below $500 \mathrm{~m} \mathrm{(950} \mathrm{hPa)} \mathrm{and}$ instead attains its largest values near and above $1000 \mathrm{~m}$ (900 $\mathrm{hPa}$ ), within the deeper potential temperature gradient at the inversion that caps the offshore boundary layer. This deeper low-stratus structure for GBM, UW, and MYNN2 is more characteristic of the cloud-topped marine planetary boundary layers typically observed in the eastern subtropics than the shallow, persistent, large- $r_{c}$ layer for YSU, MYJ, and MYJ1. The deep inversion near $1000 \mathrm{~m}$ height, at the top of the offshore marine PBL, is maintained by large-scale subsidence of warm and dry air in the eastern Pacific high pressure system (e.g., Neiburger et al. 1961).

The boundary layer thickness and stratification indicated by the potential temperature fields have consistent but quantitatively weaker differences between the schemes than those for mean $r_{c}$, with MYJ, YSU, and MYJ1 having stronger, shallower stratification than GBM, UW, and MYNN2 (Fig. 8). East of $127^{\circ} \mathrm{W}$, in the region within roughly $200 \mathrm{~km}$ of the coast, potential temperature at $1000 \mathrm{~m}$ and below increases strongly onshore at both $41^{\circ}$ and $38^{\circ} \mathrm{N}$. This horizontal potential temperature gradient in the transition region between the offshore marine and continental regimes is in part maintained by the large-scale circulation but is also affected by intermittent offshore penetration of a localized, seasonal, low-level, continental warm anomaly centered over Northern California (Fig. 9). The vertical stability caused by these offshore penetrations of warm, dry air over the coastal marine boundary layer is shown below (section 4b) to have a strong influence on coastal fog formation in some of these simulations.

\section{d. Profiles of water vapor and cloud water}

Profiles below $900 \mathrm{hPa}$ (nominal $1000 \mathrm{~m}$ height) of mean August $r_{c}, r_{v}$, and $\theta$ show distinctive contrasts between "cloudy" regions, defined for this purpose as those with mean low-level (surface to $400 \mathrm{~m}$ height, as in section $3 \mathrm{c}$ ) $r_{c}>0.03 \mathrm{~g} \mathrm{~kg}^{-1}$, and 


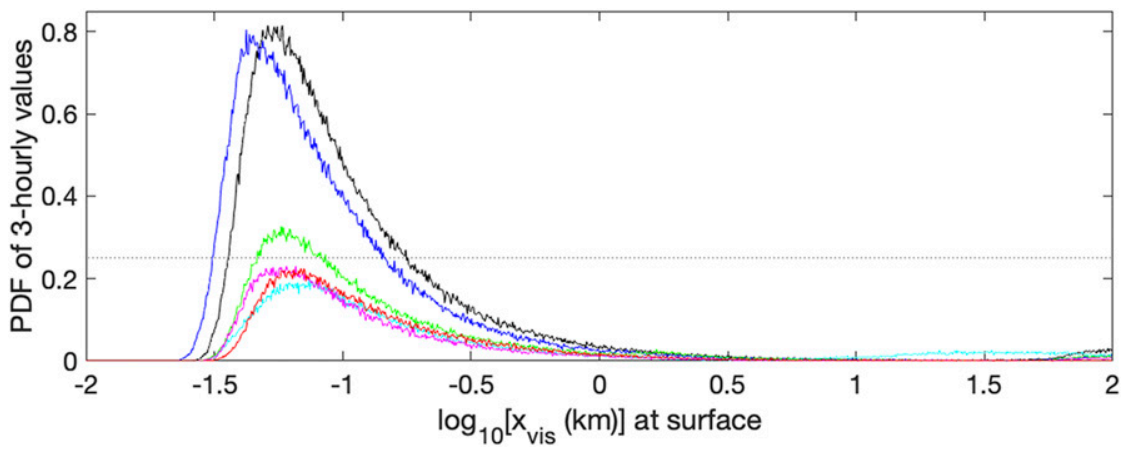

FIG. 4. August 2009 probability distribution functions of $\log _{10} x_{\text {vis }}$ (for $x_{\text {vis }}$ in $\mathrm{km}$ ) from all Aug 3-hourly output-field values in the coastal frequency-statistics subregion (Fig. 1) for MYNN2 (red), GBM (magenta), UW (green), MYJ (cyan), YSU (blue), and MYJ1 (black). The corresponding cumulative probabilities of $x_{\mathrm{vis}}<100 \mathrm{~km}$ are the total areas under each curve, which are dominated by values with $x_{\text {vis }}<1 \mathrm{~km}\left(\log _{10} x_{\text {vis }}<0\right)$. The large number of $x_{\text {vis }}$ values corresponding to the cumulative probability of $x_{\mathrm{vis}}>100 \mathrm{~km}$ are represented by the complementary area relative to a unit area, such as that beneath the indicated $0.25 \mathrm{PDF}$ value (dotted line), but are not shown directly.

"clear" regions, defined as those with mean low-level $r_{c}<$ $0.01 \mathrm{~g} \mathrm{~kg}^{-1}$. Additional dependencies on SST are seen when these means are separated by SST class: an extreme cold class with SST $<12^{\circ} \mathrm{C}$, an intermediate cool class with $12^{\circ}<\mathrm{SST}<18^{\circ} \mathrm{C}$, and a warm class with SST $>18^{\circ} \mathrm{C}$ (Fig. 10). For the cold SST class, SST $<12^{\circ} \mathrm{C}$, all of the cloudy mean $r_{c}$ profiles except those for MYJ and MYJ1 reach their respective maxima at the surface, while for the warm SST class, SST $>18^{\circ} \mathrm{C}$, all
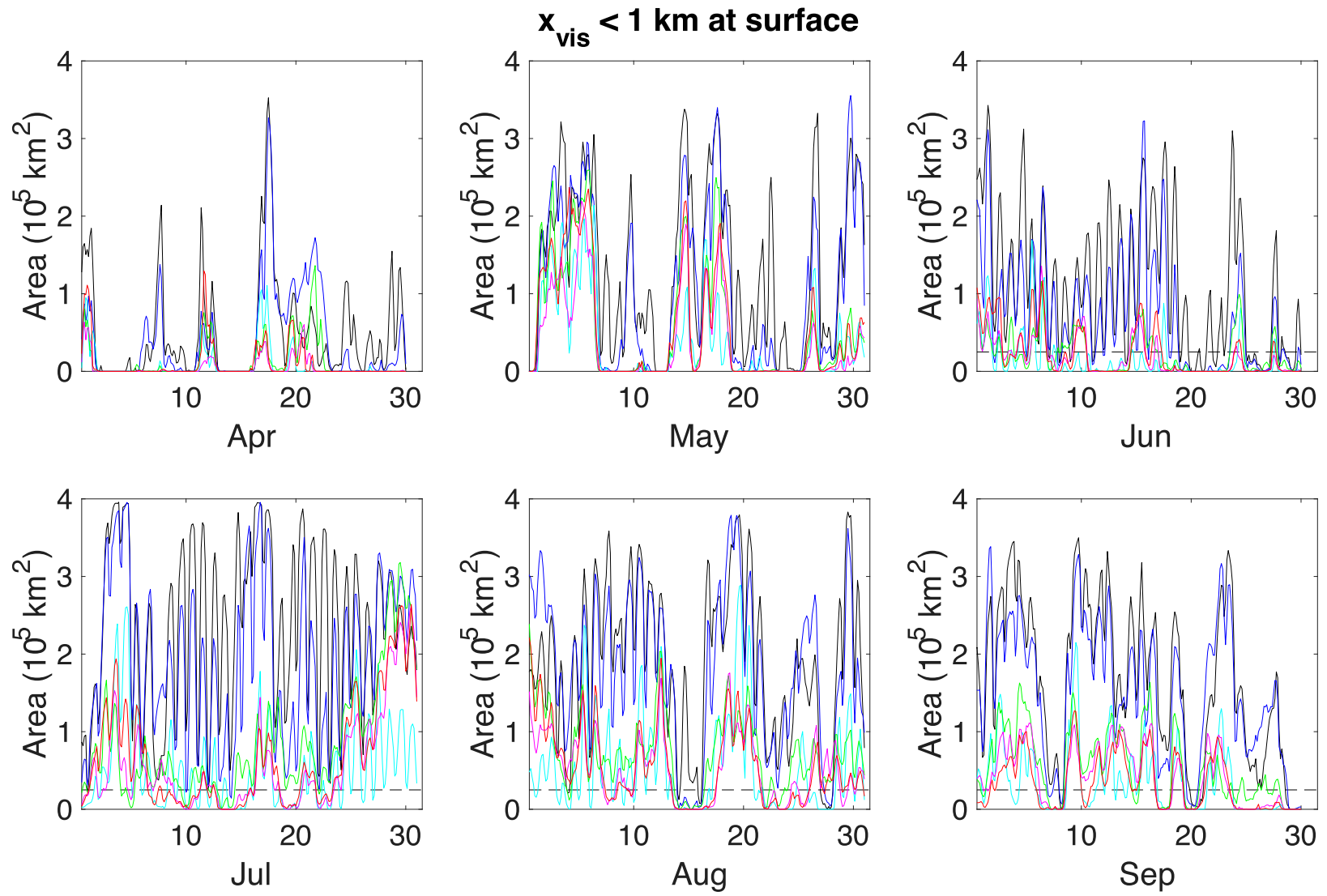

FIG. 5. Area in coastal subregion with surface visibility parameter $x_{\mathrm{vis}}<1 \mathrm{~km}$ for each 3-hourly output record of each simulation for MYNN2 (red), GBM (magenta), UW (green), MYJ (cyan), YSU (blue), and MYJ1 (black). The value $2.5 \times 10^{4} \mathrm{~km}^{2}$ used as the criterion for the vector means in Fig. 19 is indicated for June-September (dashed). 

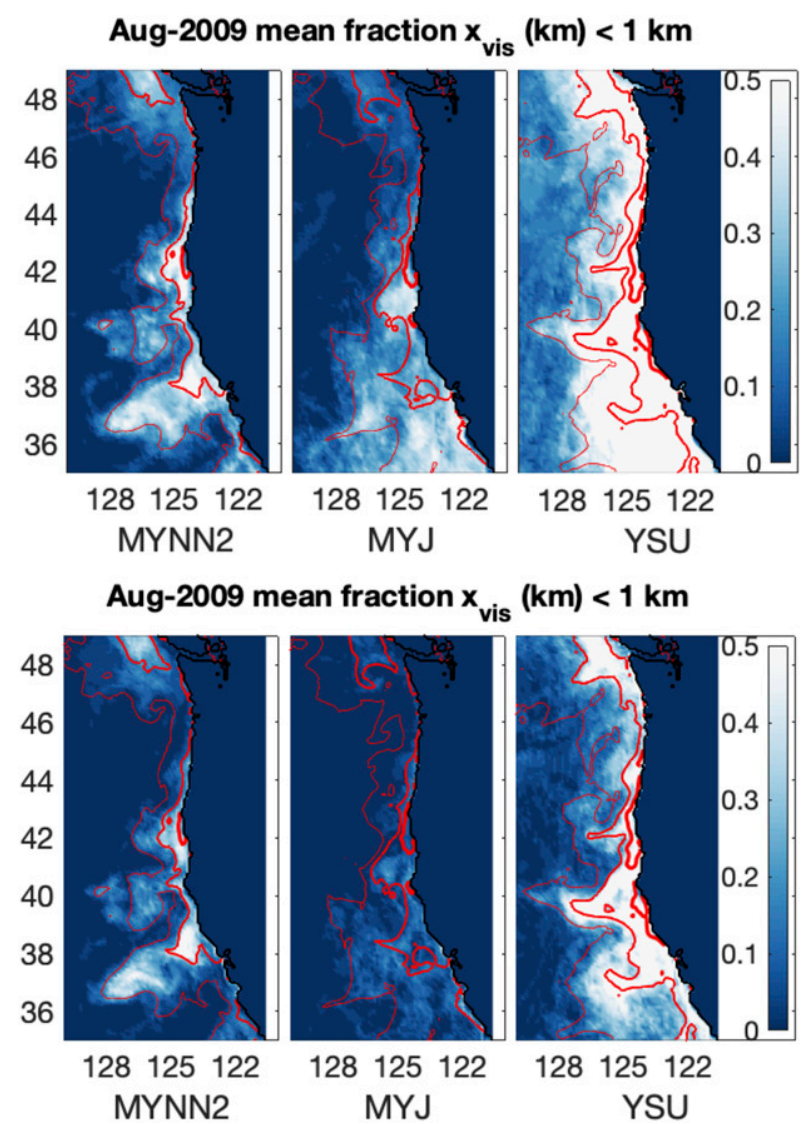

FIG. 6. August-mean surface low-visibility frequency as fraction of 3-hourly output-field values for hours (top) 12 and (bottom) 24 of each simulation day, corresponding, respectively, to the 3-hourly times of minimum and maximum insolation at the top of the atmosphere.

including MYJ and MYJ1 reach their maxima above the surface (Fig. 10, left and center-left panels). In the intermediate cool-SST range $12^{\circ}<\mathrm{SST}<18^{\circ} \mathrm{C}$, which includes most of the cloudy profiles, mean $r_{c}$ attains its maximum above the surface for YSU, MYJ, and MYJ1 and at the surface for GBM, UW, and MYNN2.

For the cold SST class, the mean surface $r_{v}$ values are essentially equal to the equivalent saturation values for the mean SSTs, as the surface $\theta$ and SST values are nearly equal, while for the intermediate and warm SST classes, the mean surface $r_{v}$ are smaller than the equivalent saturation values, and the mean surface $\theta$ values are smaller than the mean SST by as much as $3^{\circ} \mathrm{C}$ (Fig. 10, center and center-right panels). Except over the coldest SSTs, the mean cloudy profiles are systematically drier-have smaller $r_{v}$-above $950 \mathrm{hPa}$ than the corresponding mean cloud-free profiles. The mean $\theta$ profiles are progressively more stable over the colder SSTs, with a well-mixed boundary layer structure in mean $\theta$ clearly evident only for the warm SST class (Fig. 10, right panels). There is some tendency also for the cloudy profiles to be more strongly stratified above $950 \mathrm{hPa}$ than the cloudfree profiles.

\section{Conditions for fog formation}

\section{a. Surface cooling}

The approximate correspondence (Figs. 2 and 6) between the regions of cool SST from coastal upwelling and of persistent or intense coastal fog suggests that surface cooling is an important controlling factor for fog formation. The structure of the mean $r_{v}$ and $r_{c}$ profiles also suggests a causal connection between surface cooling of the lower atmosphere over cool SST and the presence of fog, with the largest mean $r_{c}$ values for most simulations found at the surface and for the coldest SST class. However, there is only a general correspondence between the cool-SST regions and the various mean fog liquidwater and visibility distributions. For example, for GBM, MYNN2, and UW there is large variability in surface $r_{c}$ and low- $x_{\text {vis }}$ probability in the intermediate-SST regions with $15^{\circ}<$ SST $<18^{\circ} \mathrm{C}$ (Fig. 2). For YSU and MYJ1, the correspondence between cool SST and fog is less systematic, while for MYJ, there is relatively little fog even over the coldest SST features.

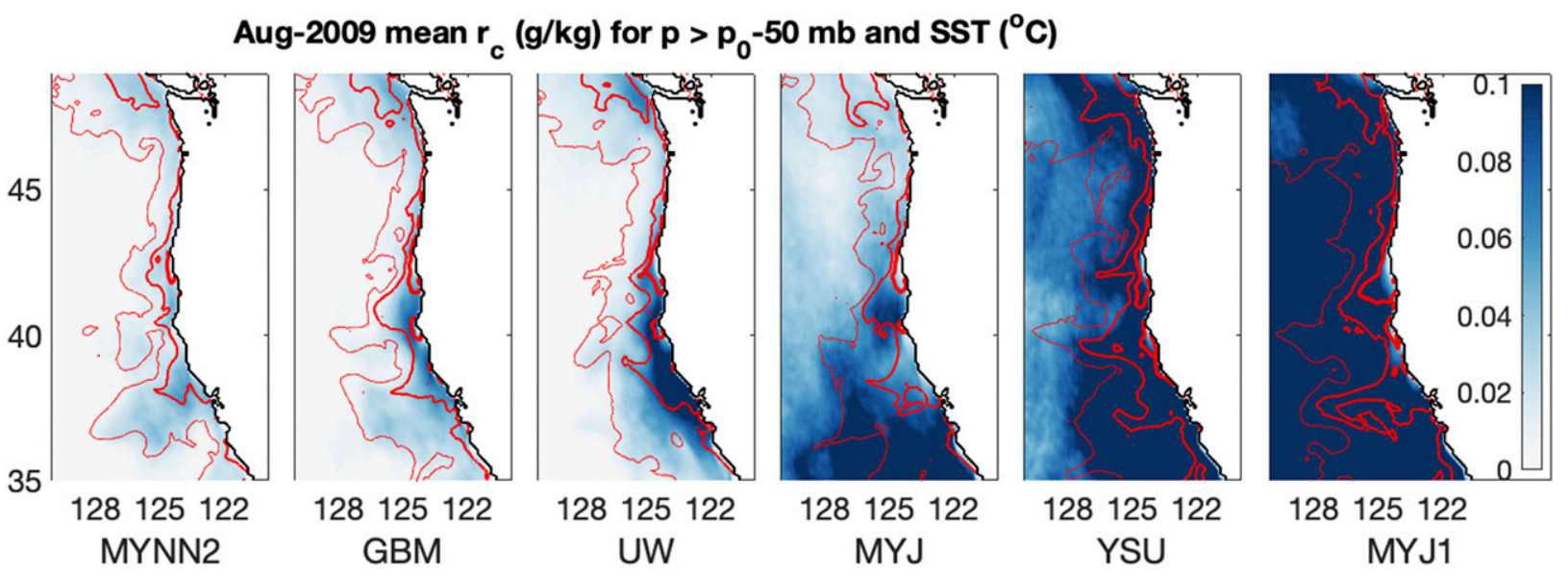

FIG. 7. As in the top panels of Fig. 2, but for low-level stratus: cloud liquid water mixing ratio $r_{c}\left(\mathrm{~g} \mathrm{~kg}^{-1}\right)$ averaged between the surface and nominal $400 \mathrm{~m}$ height (surface pressure minus $50 \mathrm{hPa}$ ). Each panel is labeled by the WRF PBL scheme used in the corresponding simulation. 
Aug-2009 $\log _{10}\left[\right.$ mean $\left.r_{c}(g / k g)\right]$ and mean $\theta(K)$ at lat $=38^{\circ} \mathrm{N}$
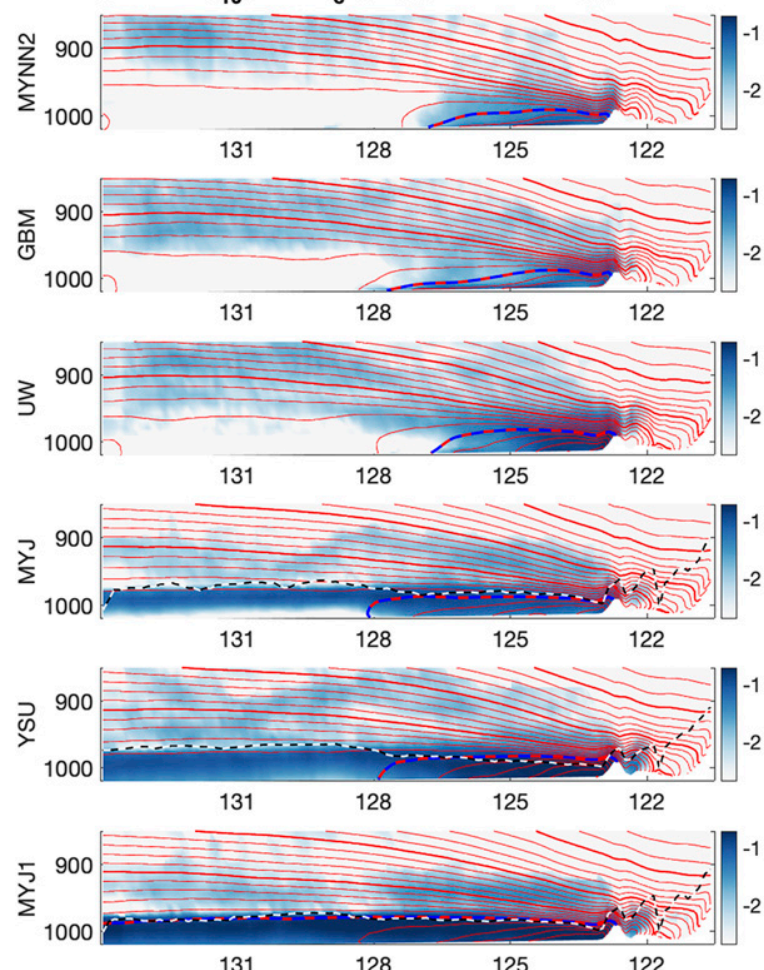

Aug-2009 $\log _{10}\left[\right.$ mean $\left.r_{c}(g / k g)\right]$ and mean $\theta(K)$ at lat $=41^{\circ} \mathrm{N}$
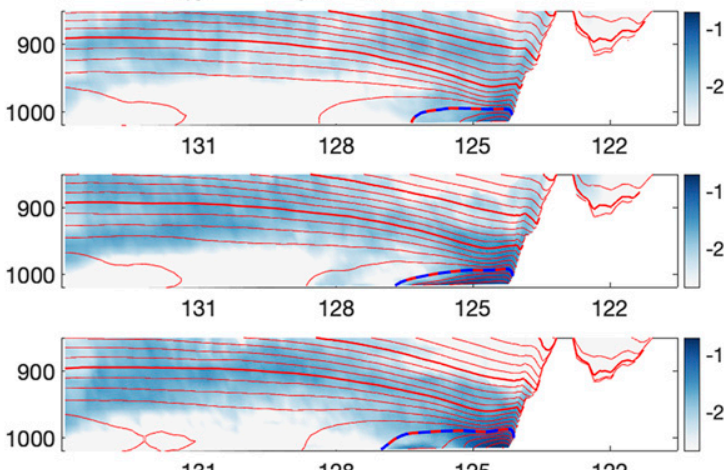

131

128

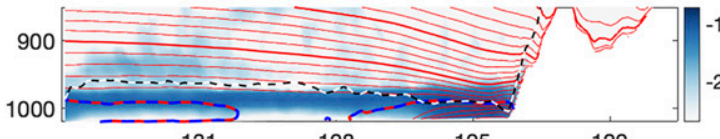

131

128

125

122

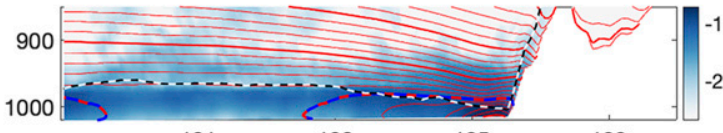

131

128

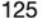

122

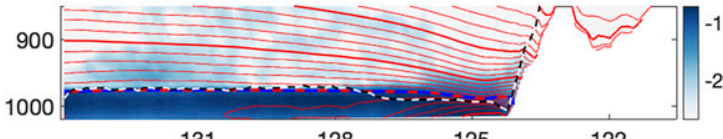

131

128

125

122

FIG. 8. Cross sections for August of the base-10 logarithm of mean $r_{c}$ (for $r_{c}$ in $\mathrm{g} \mathrm{kg}^{-1}$ ) (shading), with mean potential temperature [1 K contour intervals; thick contours at $5 \mathrm{~K}$ intervals; $290 \mathrm{~K}\left(16.85^{\circ} \mathrm{C}\right)$ contour dashed red-blue] vs longitude $\left({ }^{\circ} \mathrm{W}\right)$ and mean pressure $(\mathrm{hPa})$ at (left) $38^{\circ}$ and (right) $41^{\circ} \mathrm{N}$. Each pair of panels is labeled by the boundary layer scheme used in the corresponding simulation. (bottom three rows) For MYJ, YSU, and MYJ1, the mean diagnosed PBL height from the corresponding PBL scheme is also shown (black-white dashed line).

Over SSTs less than $12^{\circ} \mathrm{C}$, all of the mean $r_{v}-\theta$ relations for the cloudy profiles approach the saturation line toward the surface with constant $r_{v}$ and decreasing $\theta$, with surface $\theta$ slightly warmer than SST (Fig. 10, center-right panels). This suggests that fog forms by surface cooling through the condensation point over these coldest SSTs. For SST $>18^{\circ} \mathrm{C}$, the cloudy profiles have surface temperatures cooler than SST, suggesting an unstable surface layer with upward heat fluxes, for which fog formation or presence more likely arises from downward growth of a stratus layer or horizontal advection of a preexisting fog layer. For the intermediate cool-SST class, $12^{\circ}<$ SST $<18^{\circ} \mathrm{C}$, the profile structure is intermediate between these two extremes, with the difference of surface $\theta$ and SST indicating nearly neutral or slightly unstable mean conditions, depending on the simulation.

Despite these indications, the regions of surface cooling, corresponding to $H_{F}<0$ for upward surface sensible heat fluxes $H_{F}$, and of frequent fog presence are not fully coincident. For all simulations, especially MYNN2, GBM, and UW, the August mean cooling regions systematically extend farther offshore than the dominant fog presence, with their outer extent sometimes reaching $129^{\circ} \mathrm{W}$ (Fig. 11). The dominant fog regions (Fig. 2) are generally found within the regions of surface cooling, but the thickest and most frequent foggy conditions are either more narrowly confined near the coast than the cooling, for MYNN2, GBM, and UW, or are more broadly distributed and extend over regions of surface heating, for MYJ, YSU, and MYJ1.

\section{b. Vertical confinement by warm continental air}

The August mean visibility cross sections (Fig. 8) and $r_{c}$ profiles (Fig. 10) suggest that two different possible fog formation mechanisms are at work in the different simulations, both of which are likely initiated by local surface cooling over cool upwelled water. The surface maxima in the mean $r_{c}$ profiles for MYNN2, GBM, and UW are indicative of condensation at the surface that is caused directly by local surface cooling. The elevated $r_{c}$ maxima near 200-400 $\mathrm{m}$ in the profiles and cross sections for MYJ, YSU, and MYJ1, combined with the well-mixed, partly mixed, and surface-cooling-controlled structure of the $\theta$ profiles for the three SST classes (Fig. 10), are indicative of a preexisting low-level stratus layer and of fog formation by downward growth of stratus to the surface, which is induced or favored by the local surface cooling. A third possibility that is not suggested by the profiles but is also not fully ruled out is that the fog may form by advective, adiabatic lowering of the preexisting stratus layer under divergent 

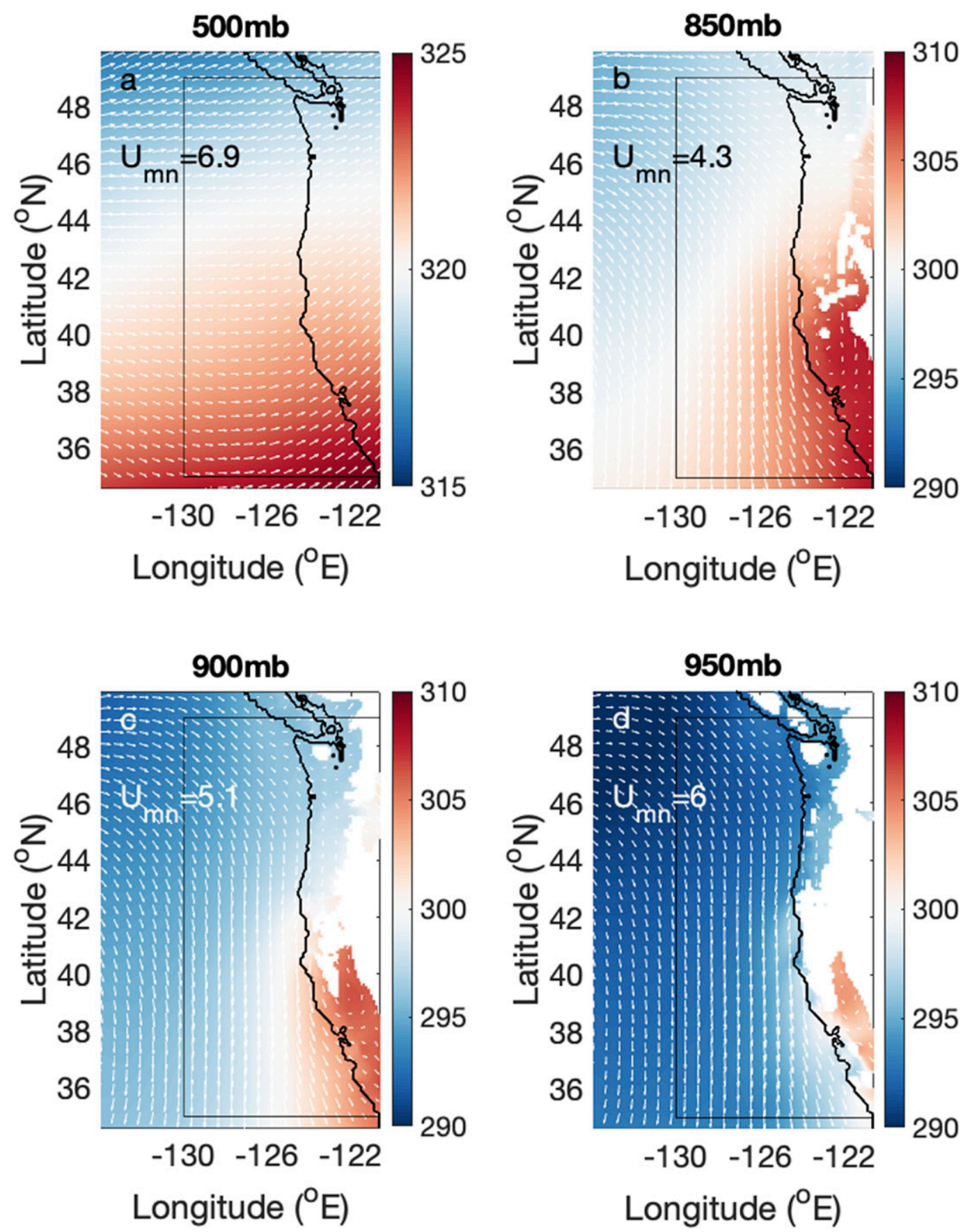

FIG. 9. Ensemble-mean August potential temperature (K) and horizontal wind velocity vectors at (a) 500, (b) 850 , (c) 900, and (d) $950 \mathrm{hPa}$. The corresponding mean wind velocity magnitudes are 6.9, 4.3, 5.1, and 6.0 $\mathrm{m} \mathrm{s}^{-1}$, respectively.

surface flow conditions, rather than by downward mixing of the elevated layer.

Additional insight into the conditions supporting fog formation by these mechanisms can be obtained by computing the height above the sea surface of the $r_{c}$ maximum in each mean profile at each point and examining its relation to the local surface heat flux. The resulting maps of atmospheric surface cooling and mean August pressure height above the sea surface of the maximum $r_{c}$ in the cloudy (mean low-level $r_{c}>$ $0.03 \mathrm{~g} \mathrm{~kg}^{-1}$ ) profiles show a strong correlation of surface maxima with regions of strong surface cooling for MYNN2, GBM, UW, and, to a lesser but still recognizable degree, YSU (Fig. 12). For MYJ and MYJ1, much broader regions of maximum $r_{c}$ several hundreds of meters above the surface (20 to 

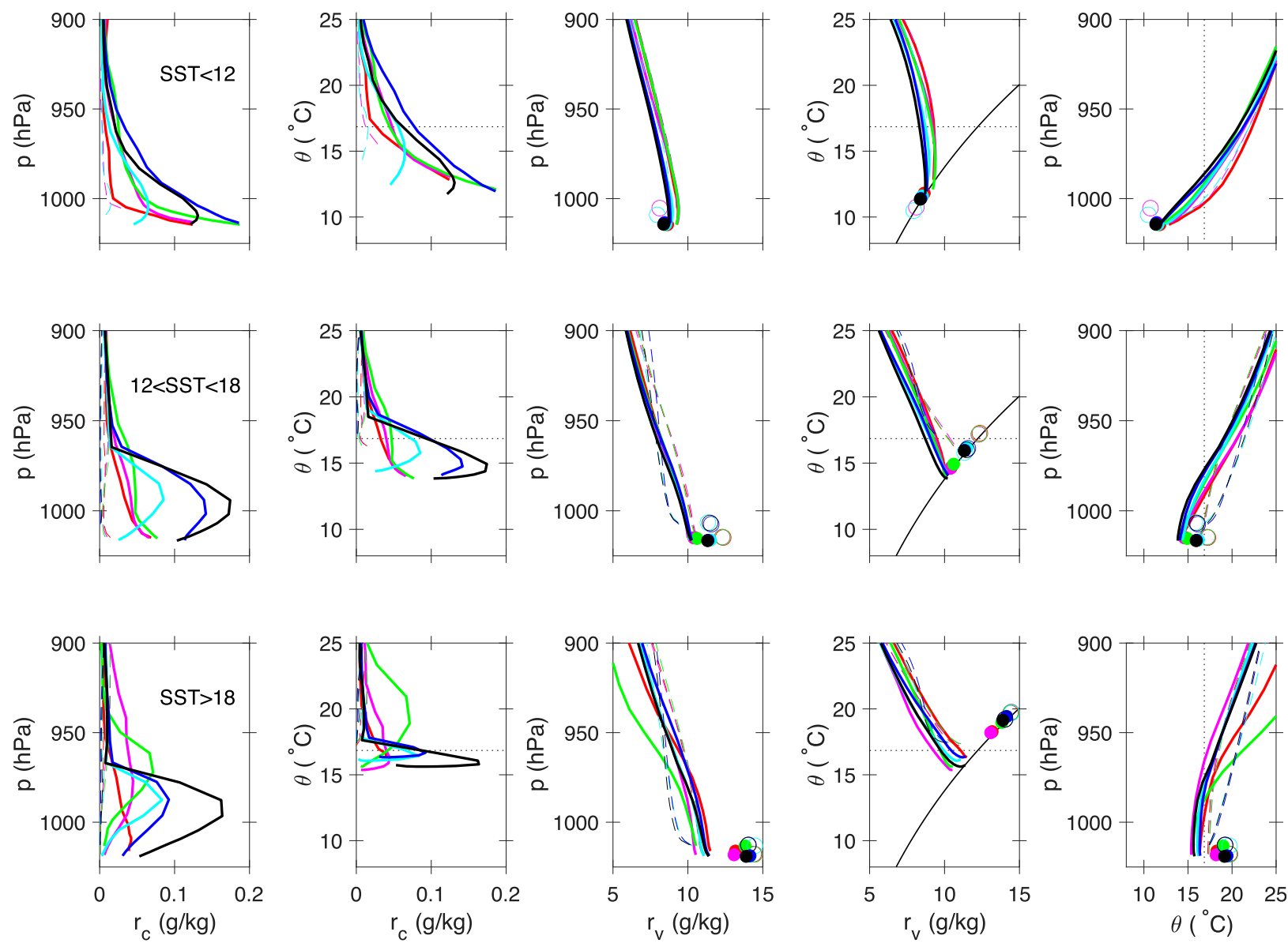

FIG. 10. Profiles of mean August liquid water $\left(r_{c}\right)$ and water vapor $\left(r_{v}\right)$ mixing ratios $\left(\mathrm{g} \mathrm{kg}^{-1}\right)$, and potential temperature $\theta\left({ }^{\circ} \mathrm{C}\right)$, for MYNN2 (red), GBM (magenta), UW (green), MYJ (cyan), YSU (blue), and MYJ1 (black). The means are taken separately for profiles with mean low-level $r_{c}>0.03 \mathrm{~g} \mathrm{~kg}^{-1}$ (solid) and mean low-level $r_{c}<0.01 \mathrm{~g} \mathrm{~kg}^{-1}$ (dashed), and for profiles with (top) SST $<12^{\circ} \mathrm{C}$, (middle) $12^{\circ}<\mathrm{SST}<18^{\circ} \mathrm{C}$, and (bottom) SST $>18^{\circ} \mathrm{C}$. Profiles are shown vs pressure (hPa) for (left) $r_{c}$, (center) $r_{v}$, and (right) $\theta$, and vs $\theta$ for (left center) $r_{c}$ and (right center) $r_{v}$, with SST and SST-equivalent saturated $r_{v}$ at surface pressure (solid and open circles for cloudy and cloud-free profiles, respectively). The saturation mixing ratio $r_{v}^{\text {sat }}(\theta)$ at the 1000 -hPa reference pressure for $\theta$ (thin black, right center panel) and the $290 \mathrm{~K}\left(16.85^{\circ} \mathrm{C}\right)$ reference-contour value of $\theta$ from Fig. 8 (dotted line; left-center, right-center, and right panels) are also shown.

$50 \mathrm{hPa}$ below surface pressure) are found, with only a broader, general correlation to the coastal cooling region. For YSU, a broad region of $r_{c}$ maxima above the surface similar to that for MYJ and MYJ1 is superposed on the surface $r_{c}$ maxima that are more closely correlated to the strong surface cooling regions. For MYNN2, GBM, and UW, the cloudy profiles are essentially all confined to regions of strong surface cooling, and the $r_{c}$ maxima are essentially all at the surface. There is no suggestion in these maps of a downwind, advective lowering of the $r_{c}$ maximum that would correspond to the third, adiabatic, divergent flow mechanism. Instead, for MYNN2, GBM, and UW there is an abrupt transition from $r_{c}<0.03 \mathrm{~g} \mathrm{~kg}^{-1}$ throughout the profile to surface $r_{c}>0.03 \mathrm{~g} \mathrm{~kg}^{-1}$ at the upwind edges of strong cooling regions adjacent to the coast, while for MYJ and MYJ1, there is a general lowering of the maximum $r_{c}$ layer toward the coast, with a mild enhancement in the local surface cooling regions. The YSU simulation shows a superposition of these two.

These comparisons thus support the conclusion that fog formation in MYNN2, GBM, and UW occurs by condensation of liquid water vapor at the surface that is caused directly by local surface cooling, while that in MYJ and MYJ1 occurs by downward growth of a preexisting low-level stratus layer, which is generally induced or favored by surface cooling across the broader coastal region. For YSU, both mechanisms evidently occur, with surface condensation localized in the regions of strong cooling, and downward growth contributing throughout the broader coastal region. Even for MYNN2, GBM, UW, and YSU, however, these maps do not show a unique relationship between surface cooling and surface $r_{c}$-maxima, as there are offshore regions of strong surface cooling that remain cloud-free up to $50 \mathrm{hPa}(400 \mathrm{~m})$ above the surface for MYNN2, GBM, and UW, and have only elevated $r_{c}$-maxima for YSU (Fig. 12). 


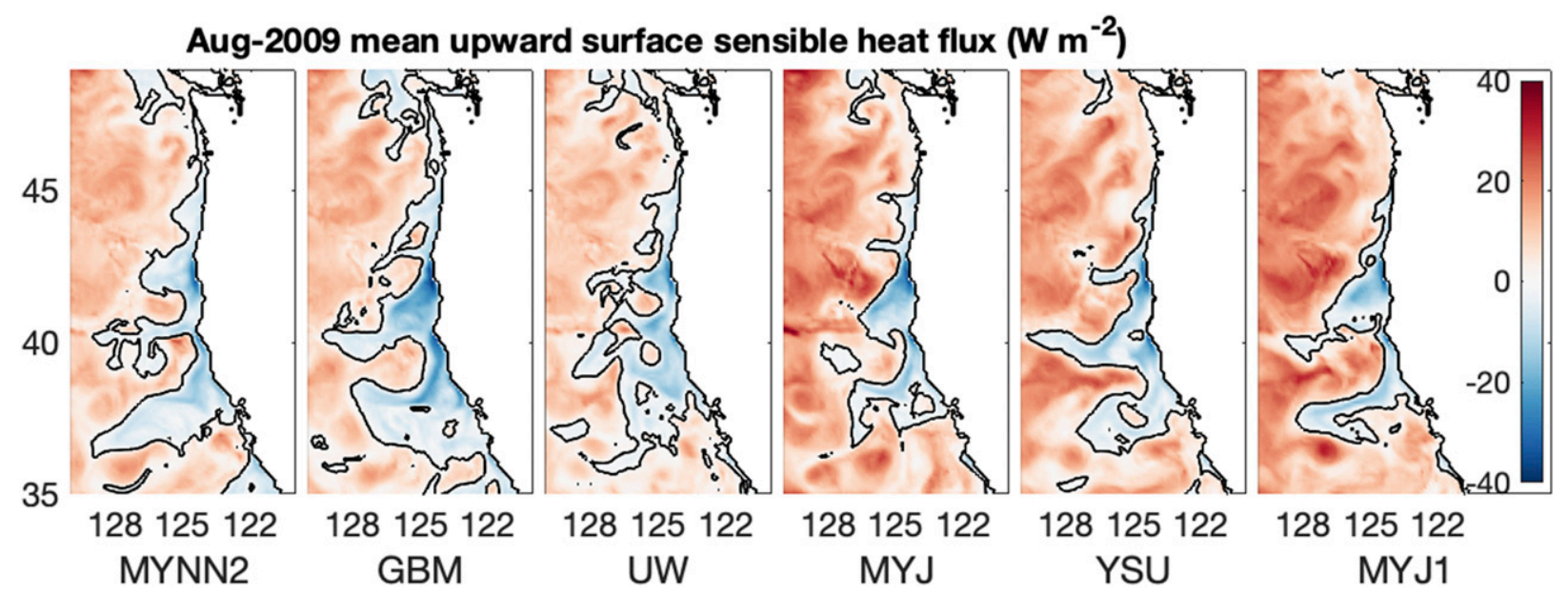

FIG. 11. August mean of upward sensible surface heat flux $H_{F}\left(\mathrm{~W} \mathrm{~m}^{-2}\right.$; shading; black line: zero contour $)$. A value of $H_{F}>0$ corresponds to heat flux into the atmosphere. Each panel is labeled by the WRF PBL scheme used in the corresponding simulation.

The additional necessary and sufficient condition for fog formation at the surface in these simulations is evidently enhanced vertical stability from the offshore penetration (Fig. 9) of warm, dry air above the marine boundary layer. The offshore extent of this warm, dry air mass can be measured by the potential temperature difference between the surface and a level within or above the upper part of the inversion capping the boundary layer over the ocean. When this extent is measured by the potential temperature difference $\Delta \theta_{850}$ between the surface and $850 \mathrm{hPa}$, the contour $\Delta \theta_{850}=15 \mathrm{~K}$ closely marks the boundary in each of these simulations between the strong surface cooling regions that show fog formation inshore and those that remain cloud-free offshore in the August mean (Fig. 12). Note that this sharp boundary between the fog-formation and cloud-free regions is not marked by any strong cross-shore gradients in surface heat flux within the surface cooling regions (Fig. 11). The possible control of fog formation by this warm continental air intrusion has been mentioned already by Leipper (1948) but is suggested independently by these simulations.

\section{c. Sensible and radiative flux effects}

The radiative component of the lower atmosphere heat budget may be characterized by the difference in net radiative fluxes at $850 \mathrm{hPa}$ and the surface, and combined with the surface sensible heat flux $H_{F}$ to show the dominant diabatic influences on fog and low-level stratus formation. Time series of these terms during August, averaged over the different regions delineated by the sign of the surface heat flux and the mean August $\Delta \theta_{850}=15 \mathrm{~K}$ contour (Fig. 12),

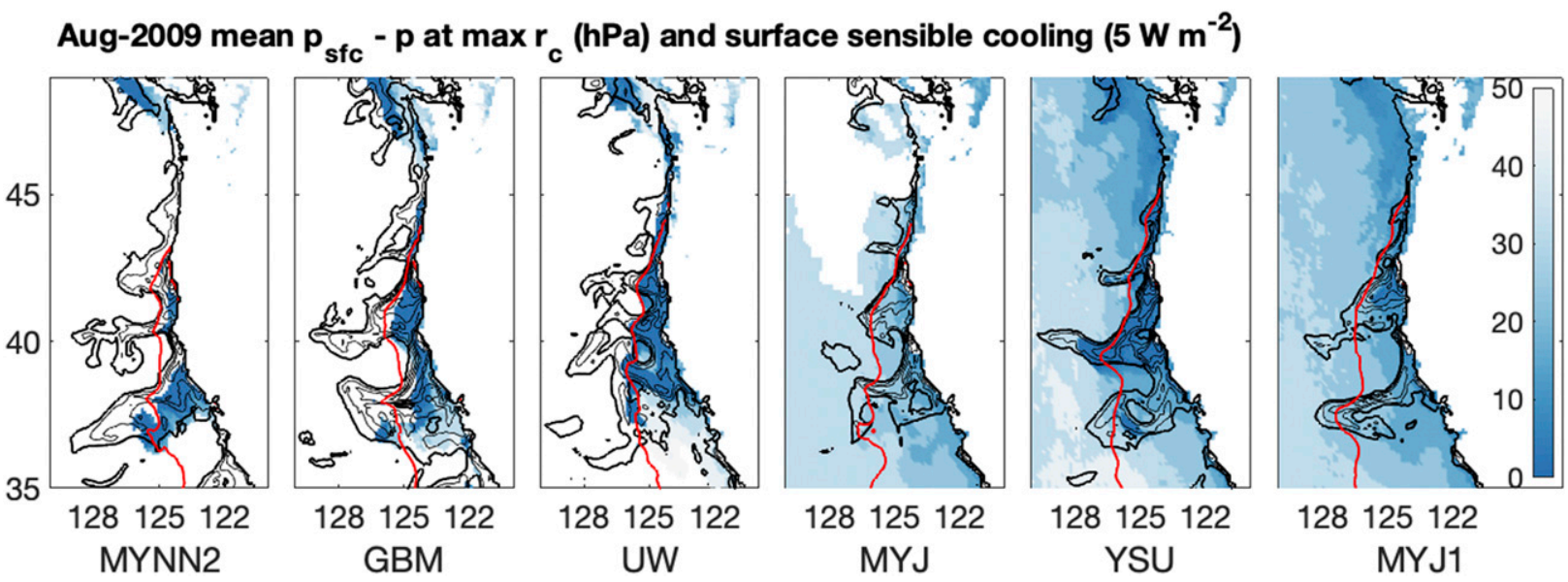

FIG. 12. August mean of pressure height above surface of maximum $r_{c}$ for cloudy regions (hPa; shading), with contours of downward sensible heat flux $-H_{F}$ (black; $5 \mathrm{~W} \mathrm{~m}^{-2}$ contour interval; zero contour thick; negative contours not shown) and the $\Delta \theta_{850}=15 \mathrm{~K}$ contour (red) of the difference field of potential temperature $\theta$ at nominal $850 \mathrm{hPa}$ height and at the surface. Only the regions of surface sensible cooling of the atmosphere $\left(H_{F}<0\right)$ are contoured; the full sensible heat flux field $H_{F}$ is shown in Fig. 11 . Each panel is labeled by the WRF PBL scheme used in the corresponding simulation. 

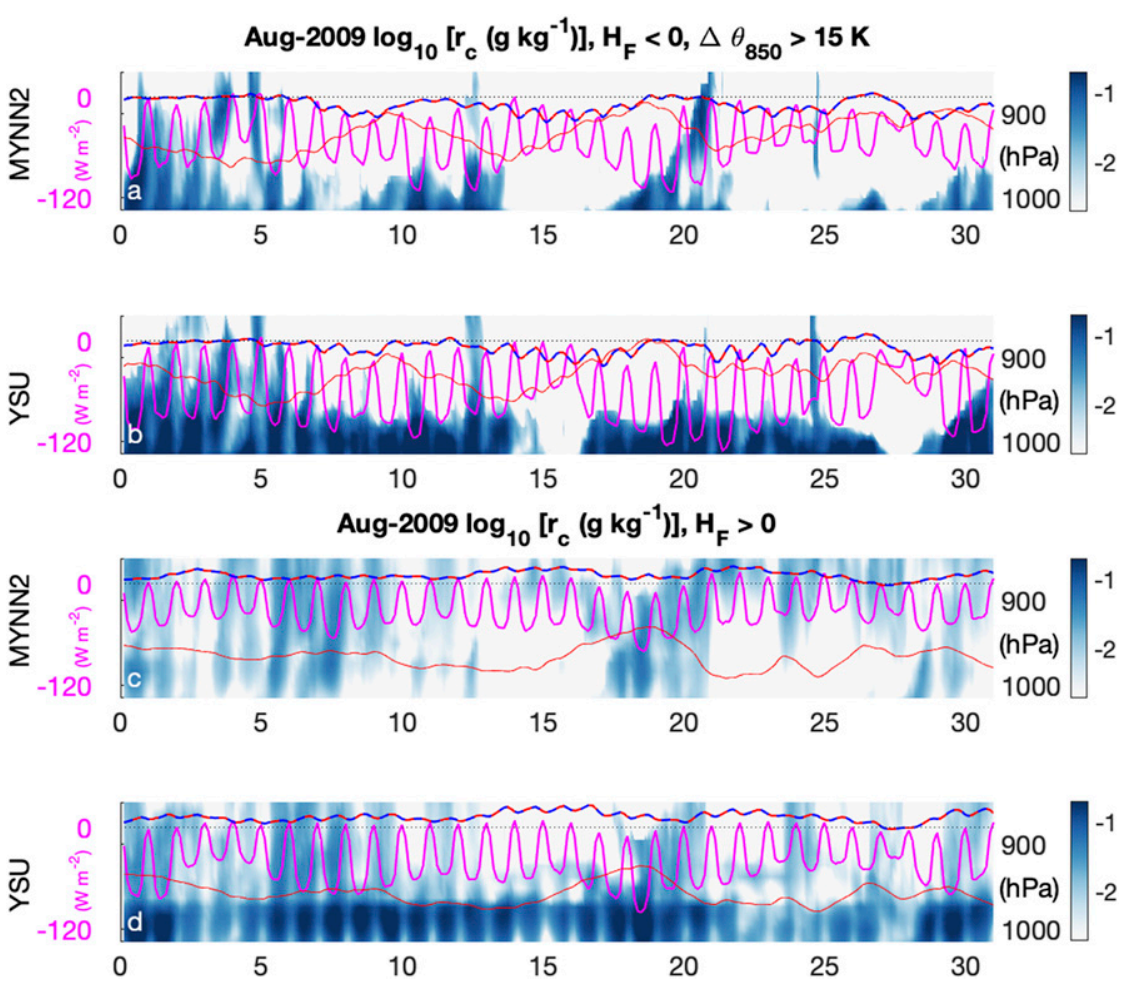

FIG. 13. Vertical profiles of cloud liquid water $r_{c}\left(\log _{10}\right.$ of $\mathrm{g} \mathrm{kg}^{-1}$; shading) vs nominal mean pressure (hPa) and time (day in August) for two different conditional spatial averages taken with reference to the monthly mean fields shown in Fig. 12. The spatial averages are taken over the regions with (a),(b) monthly mean surface cooling $\left(H_{F}<0\right)$ and $\Delta \theta_{850}>15 \mathrm{~K}$ and (c),(d) monthly mean surface heating $\left(H_{F}>0\right)$ for (a),(c) MYNN2 and (b),(d) YSU. Also shown are the instantaneous values of corresponding spatial averages of $H_{F}$ (dashed blue-red line), heating from net radiative fluxes between $850 \mathrm{hPa}$ and the surface (magenta line), and $\Delta \theta_{850}$ (red solid line). The latter are shown on linear scales relative to the pressure axis, with reference values of 0 and $-120 \mathrm{~W} \mathrm{~m}^{-2}$ at 880 (dotted black) and $1000 \mathrm{hPa}$, respectively, on the pressure axis for the fluxes, and reference values of 25 and $0 \mathrm{~K}$ at 880 and $1015 \mathrm{hPa}$, respectively, for $\Delta \theta_{850}$. The nominal pressure values are the spatiotemporal and ensemble means over the full domain for August for all simulations for each model vertical level, relative to a nominal mean surface pressure $1015 \mathrm{hPa}$, and each panel is labeled by the WRF PBL scheme used in the corresponding simulation.

and superposed on similar averages of vertical profiles of $r_{c}$ provide additional illustration of the different characteristic fog formation processes (Fig. 13).

Frequent surface-formation events with no preceding elevated stratus layer are evident for MYNN2 for the region with mean surface cooling and mean $\Delta \theta_{850}>15 \mathrm{~K}$ (Fig. 13a), with these events tending follow surface cooling events with instantaneous spatial-mean $\Delta \theta_{850}>15 \mathrm{~K}$. In contrast, for YSU in the region with mean surface heating (Fig. 13d), there is a persistent stratus layer near $980 \mathrm{hPa}$, with clearing at lower levels followed by downward extension of the stratus to the stratus often occurring on diurnal time scales, with cooling and lowering during the night and surface clearing or partial clearing during the day. The formation processes are less clearly distinguished for YSU in the region with mean surface cooling and mean $\Delta \theta_{850}>15 \mathrm{~K}$ (Fig. 13b) and for MYNN2 in the region with mean surface heating (Fig. 13c). The averages over the remaining region, with mean $H_{F}<0$ but mean $\Delta \theta_{850}<15 \mathrm{~K}$, are intermediate between these two extremes.

Even in the individual events that can be distinguished in this way, however, the detailed cloud liquid water and radiation budgets are complicated and time dependent. For example, the event during 17-22 August for MYNN2 (Fig. 13a) shows initial surface formation in response to surface cooling but is followed by upward growth of a cloud layer that becomes detached from the surface, which must be controlled by radiative fluxes.

\section{d. Moisture advection}

At the upwind, northern edges of the surface $r_{c}$ maxima, positive horizontal surface moisture advection $\left(-\mathbf{u}_{h} \cdot \nabla_{h} r_{v}>0\right)$ and negative horizontal surface cloud liquid water advection $\left(-\mathbf{u}_{h} \cdot \nabla_{h} r_{c}<0\right)$ are coincident in the August mean (Fig. 14). This correspondence would be consistent with conversion of advected water vapor to fog by cooling-induced condensation of water vapor at the surface in these regions of surface cooling 


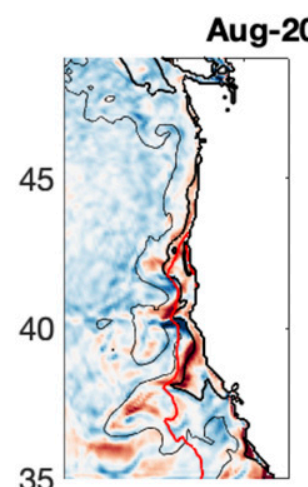

128125122

MYNN2

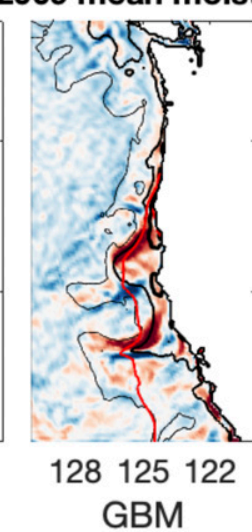

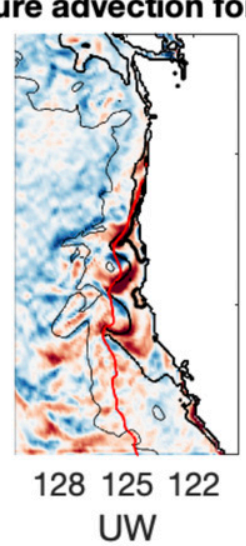

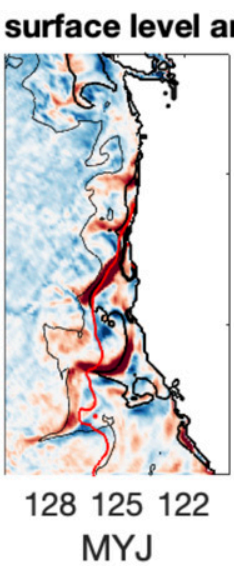

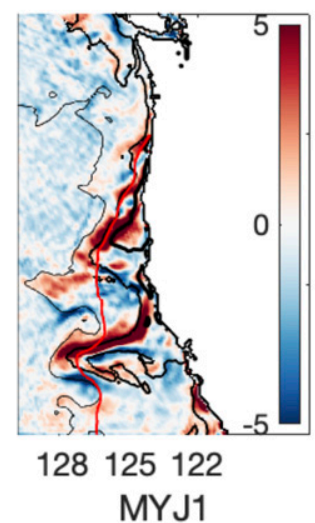

Aug-2009 mean cloud liquid water advection for surface level and SST

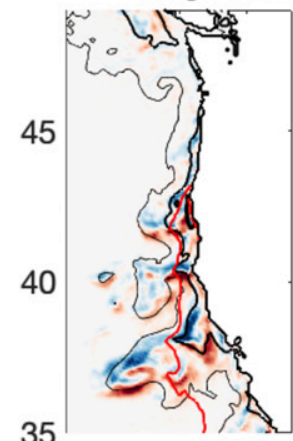

128125122

MYNN2
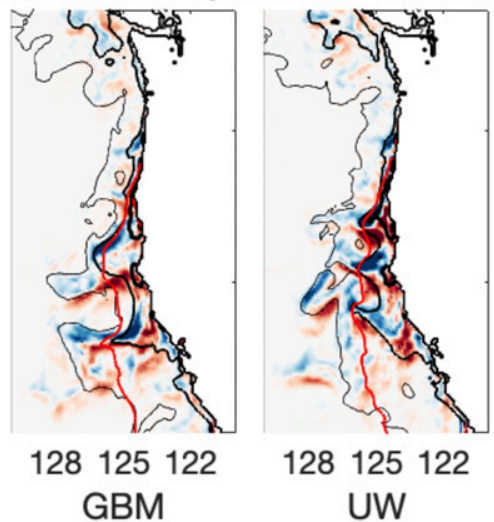
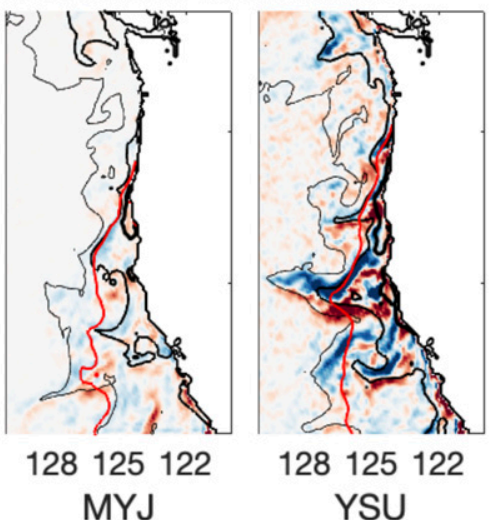

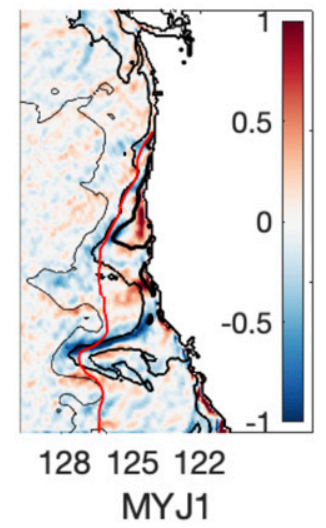

FIG. 14. Mean August horizontal advection of (top) water vapor mixing ratio, $-\mathbf{u}_{h} \cdot \nabla_{h} r_{v}$, and (bottom) cloud liquid water mixing ratio, $-\mathbf{u}_{h} \cdot \nabla_{h} r_{c}$, at the surface $\left(10^{-5} \mathrm{~g} \mathrm{~kg}^{-1} \mathrm{~s}^{-1}\right.$; shading). The $12^{\circ}$ (thick), $15^{\circ}$, and $18^{\circ} \mathrm{C}$ (thin) SST contours (black) and the $\Delta \theta_{850}=15 \mathrm{~K}$ contour (red) of the difference field of potential temperature $\theta$ at $850 \mathrm{hPa}$ and at the surface are also shown. Each panel is labeled by the WRF PBL scheme used in the corresponding simulation.

and vertical confinement. Immediately downwind of the surface $r_{c}$ maxima, horizontal moisture advection is generally negative, indicating evaporation of the fog at the surface in regions of surface warming and consistent with the lifting of the $r_{c}$ maxima off the surface in these regions (Fig. 12). In both cases, there is only partial compensation between the vapor advection and the liquid water advection, consistent with the inferred importance of vertical mixing and turbulent vertical moisture fluxes in fog formation, which would remove some of the surface-condensed fog and distribute it more deeply through the boundary layer. Surface cloud liquid water advection is particularly weak for MYJ, because of the low surface $r_{c}$ values.

The magnitude of the water vapor advection features for YSU, MYJ, and MYJ1 is as large or larger than those for GBM, UW, and MYNN2, consistent with an effect of surface cooling on fog formation over the cold, upwelled water also in the MYJ, YSU, and MYJ1 simulations, which have a much broader distribution of low stratus above the surface. For MYJ, either vertical mixing is strong enough near the surface and in the stratus-capped boundary layer to maintain an elevated $r_{c}$ maximum even in these fog formation regions, or the low-level stratus layer is strong enough to maintain itself by supporting a radiatively controlled, elevated, cool anomaly.

\section{e. Seasonal variations: Dependence on offshore SST}

These simulations extend from March to mid-October 2009 and consequently allow examination of the seasonal progression from April to September. In April 2009, the atmospheric circulation is still dominated by late-winter, early spring patterns, with a zonal progression of synoptic disturbances. This results in an entirely different mean surface $r_{c}$ structure in April than in June and the subsequent summer months, with mean $r_{c}$ in April generally increasing offshore rather than onshore (Fig. 15). The low-visibility events in the time series of coastal-zone area with $x_{\text {vis }}<1 \mathrm{~km}$ (Fig. 5) thus have a different synoptic origin in April 2009 than during the summer.

The months of May and June 2009 are transitional, with the northerly summertime flow generally well-established by June, for which the coastal fog events are again associated primarily with the cool coastal SST structure (Fig. 15). In July and September, the monthly mean fog and low stratus patterns and formation processes are similar to those for August 2009. Mean 
Apr-2009 mean $r_{c}(\mathbf{g} / \mathbf{k g})$ for surface level
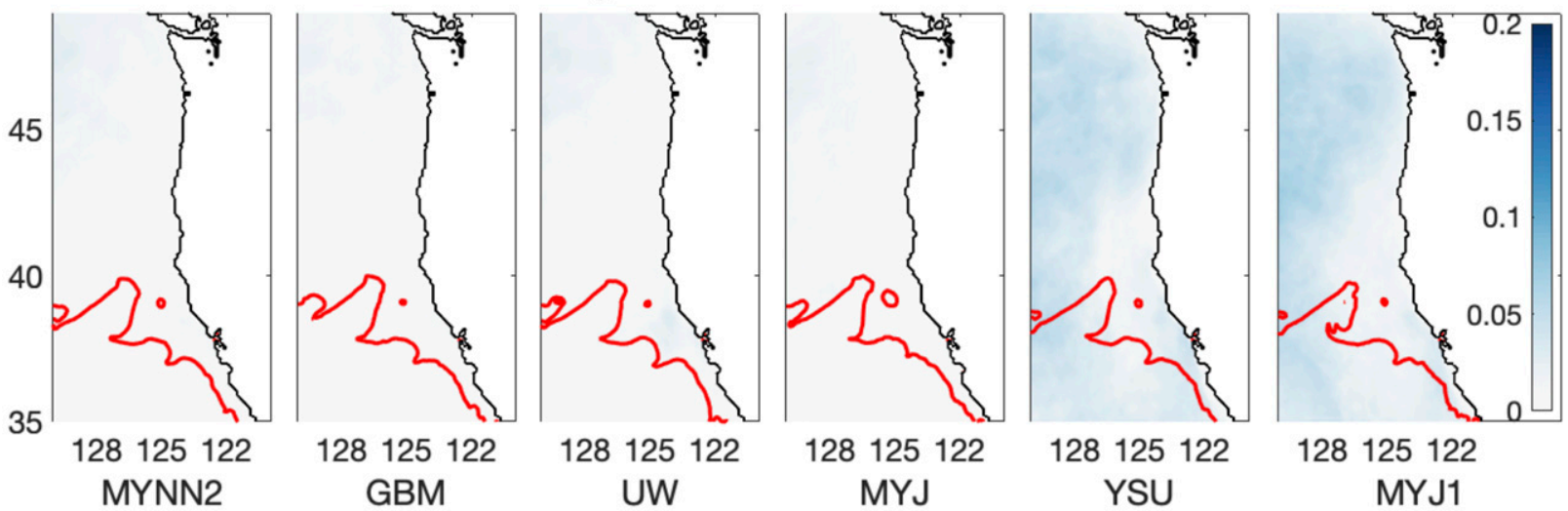

Jun-2009 mean $r_{c}(g / k g)$ for surface level
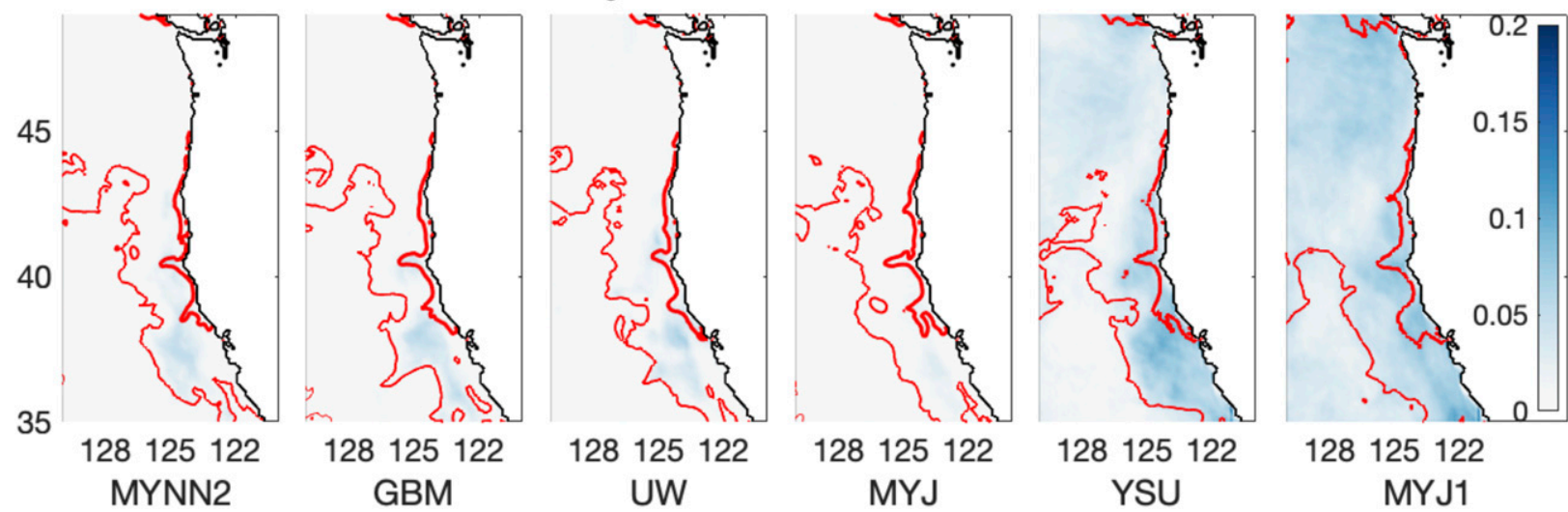

FIG. 15. Mean surface $r_{c}\left(\mathrm{~g} \mathrm{~kg}^{-1}\right)$ for (top) April and (bottom) June 2009. Each panel is labeled by the WRF PBL scheme used in the corresponding simulation.

winds for September are weaker than those for July and August, and the warm continental-air anomaly is confined nearer to the coast in September, but upwelling is sufficient to maintain cool SSTs along the coast. Consequently, the cloudy regions (mean low-level $r_{c}>0.03 \mathrm{~g} \mathrm{~kg}^{-1}$ ) tend to be more tightly confined near the coast in September than in August. Fog also occurs offshore of the cloudy regions in September, and is evidently less controlled by the vertical confinement associated with the warm continental air in September than in August, perhaps because of weaker vertical mixing associated with the weaker mean winds.

Although the correlation of mean coastal fog with cool coastal SST is established by June, fog and low-stratus formation is markedly weaker in June (Fig. 15) than in August (Fig. 2), especially for the MYNN2, GBM, and UW simulations. Mean winds are similar in the two months, and mean SST along the coast is as cold in June (Fig. 16) as in August (Fig. 1), so the source of this difference is not weaker winds or warmer coastal SSTs. The warm continental air above the boundary layer does not penetrate as far offshore in June as later in the season, but in June there is little surface fog or low-level cloud over the cool SSTs even in the narrower coastal band where the resulting vertical confinement occurs. The proximate cause of this difference in fog and low-stratus formation for MYNN2, $\mathrm{GBM}$, and $\mathrm{UW}$ is the reduced moisture content in June $\left(r_{v} \approx\right.$ $8 \mathrm{~g} \mathrm{~kg}^{-1}$ ) relative to August $\left(r_{v} \approx 11 \mathrm{~g} \mathrm{~kg}^{-1}\right)$ of the low-level air that is advected southward and onshore over the cool coastal SSTs (Fig. 17). For MYJ, YSU, and MYJ1, for which the fog formation evidently derives primarily from downward growth of the low-level stratus, there is less difference between the June and August fog distributions.

The different simulated coastal fog and low-level stratus responses in June relative to the later summer months arise from seasonal changes in the contrast between offshore and coastal SST, which are in turn driven by surface heating offshore. The greater moisture content of the upstream, offshore low-level air in August relative to June in turn arises from solar heating of the ocean surface, which result in SST in the region north and west of the coastal fog zone that is $4^{\circ} \mathrm{C}$ greater in August than in June (Figs. 1 and 6). In contrast, the coldest SST adjacent to the coast is maintained at a nearly constant $12^{\circ} \mathrm{C}$ by coastal upwelling throughout the upwelling season, from June to September. Consequently, the cooling and condensation effects on the advected low-level air are much stronger in August (and July and September) than in June, because of the greater local ocean-atmosphere temperature difference and 

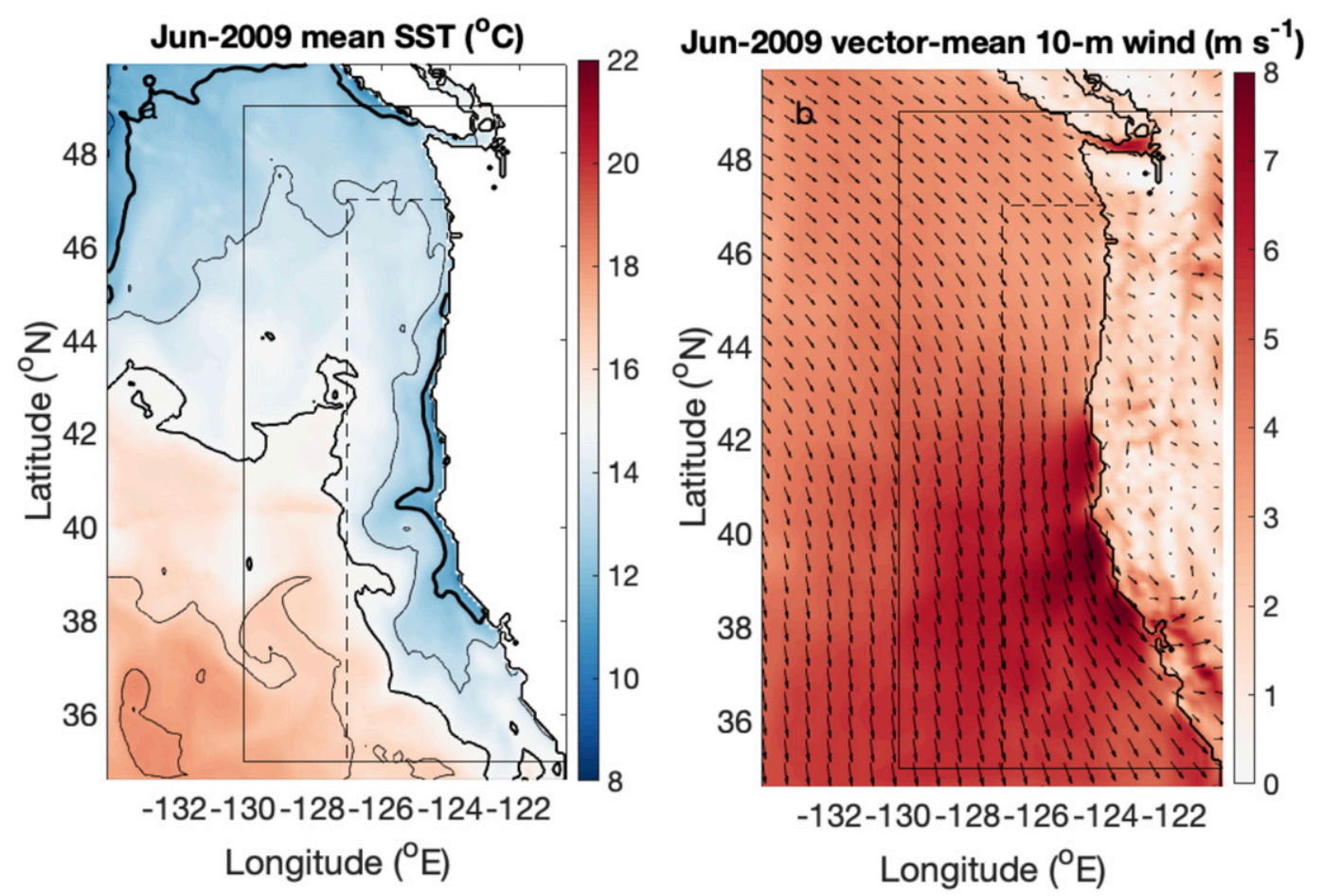

FIG. 16. As in Fig. 1, but for June.

the greater low-level atmospheric moisture content. This results in greater local fog formation in the later summer than in June. Perhaps surprisingly, the relative (rather than specific) humidity of the low-level offshore air is $5 \%$ lower in July and August than in June, presumably because of stronger radiative heating of the relatively cool low-level atmosphere during those later months, which warms the lowlevel air farther above the condensation point despite its greater moisture content. Nonetheless, the surface cooling in July, August, and September is able to overcome the slightly reduced upstream relative humidity during those months and support enhanced fog formation as the moist air, with its enhanced specific humidity relative to June, is advected over the cold upwelled water.

\section{f. Synoptic variations: Dependence on offshore flow}

Large fluctuations in low-visibility area in the coastal zone in these simulations also occur during the upwelling season on shorter, synoptic time scales (Fig. 5). These are evidently also largely controlled by variations in moisture advection. On the synoptic time scales, however, the fluctuations arise from changes not in offshore SST but in the direction of surface winds. A suitable criterion for distinguishing between generally clear-sky and generally foggy coastal conditions is whether the area with $x_{\text {vis }}<1 \mathrm{~km}$ in the coastal subregion is, respectively, less than or greater than $2.5 \times 10^{4} \mathrm{~km}^{2}$ (Fig. 5). Separate means computed for clear-sky and foggy conditions from 3hourly states during June-September that are distinguished by this criterion show intensification of a shift from northwesterly to intensified northerly surface flow and drier air in the coastal zone and just offshore during the clear-sky periods, relative to the foggy periods (Figs. 18 and 19). This structure of the difference fields is consistent for all of the simulations, though slightly weaker for MYJ. The intensified northerly surface flow during clear conditions is accompanied by an offshore flow component at and above the inversion height north of $42^{\circ} \mathrm{N}$.

This comparison suggests that, on synoptic time scales, the interruption of foggy conditions in the coastal zone during the upwelling season arises from offshore and southward flow of continental air that reduces the moisture level of the surface air encountering the cool SST in the coastal upwelling zone. The intensified northerly flow during these clear-sky conditions will also drive an enhanced upwelling response, further reducing coastal SST, so that foggy conditions will return rapidly with northwesterly flow and the associated advection of warm, moist offshore air into the coastal zone. Note that the offshore flow for clear-sky conditions is associated with intensification of the continental thermal low and extension of the warm, dry continental air offshore. This is the same warm continental air that causes enhanced fog formation over the cool SST by reducing vertical mixing at the shallow, coastal zone PBL inversion when its offshore extension is less extreme and the dry air remains above the PBL (section $4 \mathrm{~b}$ ) rather than reaching the surface.

\section{Discussion}

\section{a. U.S. West Coast fog}

Fog along the U.S. West Coast has been an object of study by numerous investigators, including those cited in the introduction (section 1). Useful reviews of this literature are available 

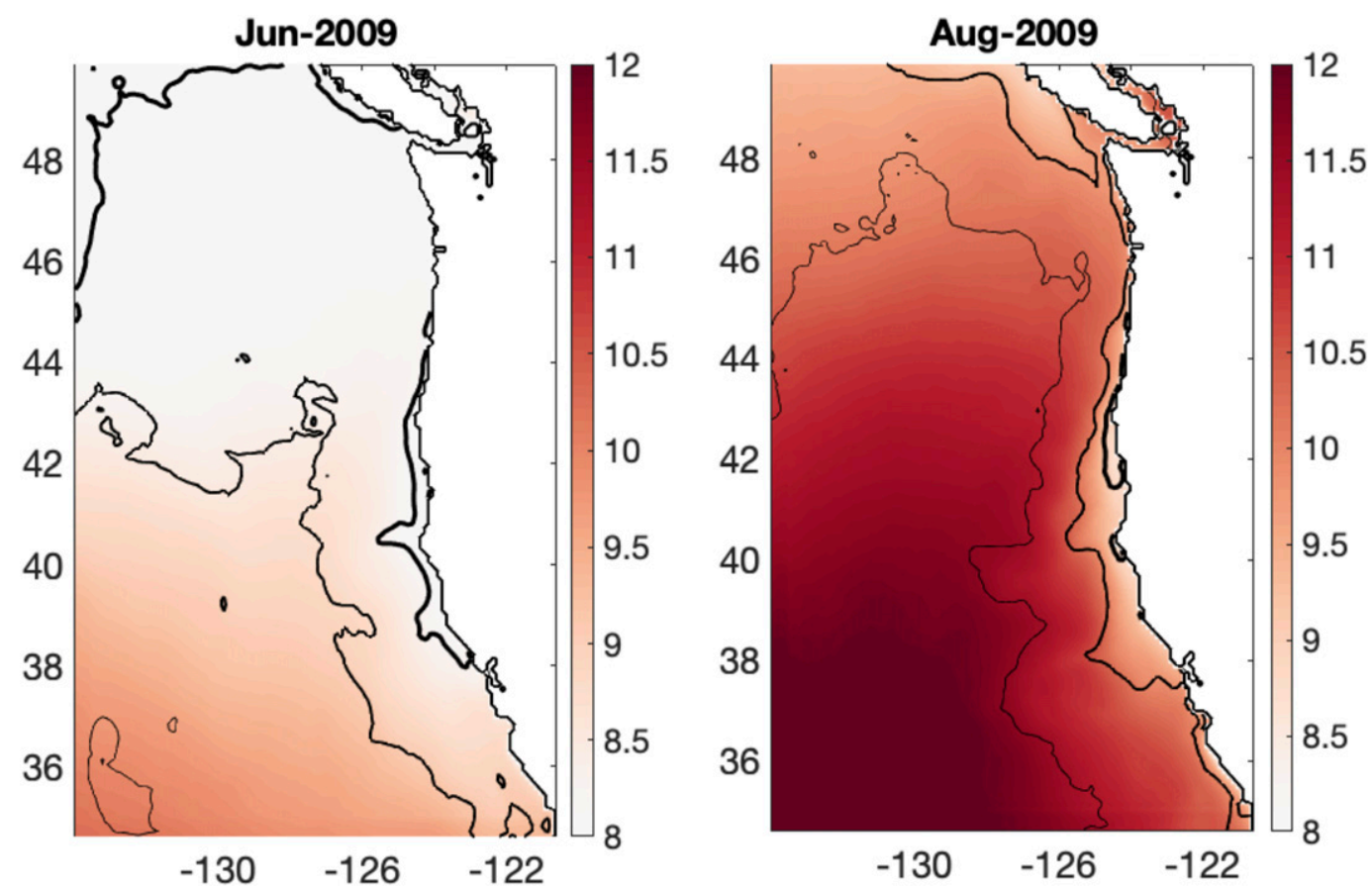

FIG. 17. Ensemble-mean (top) June and (bottom) August 2009 water vapor mixing ratio $r_{v}\left(\mathrm{~g} \mathrm{~kg}^{-1}\right)$ at the surface vs longitude $\left({ }^{\circ} \mathrm{W}\right)$ and latitude $\left({ }^{\circ} \mathrm{N}\right)$. The $12^{\circ}$ (thick) and $15^{\circ} \mathrm{C}$ SST contours for June and the $12^{\circ}$ (thick), $15^{\circ}$, and $18^{\circ} \mathrm{C}$ (thin) SST contours for August are also shown (black).

in Koračin et al. (2014), Leipper (1994), and Koračin (2017). Despite this previous work, considerable uncertainty remains regarding the dominant mechanisms of fog occurrence in this regime. McEwen (1912) originally hypothesized that the primary fog formation mechanism along the central California coast in summertime was condensation induced by surface cooling as moist air was advected over colder sea surface temperatures. In contrast, and independently, Anderson (1931) and Petterssen (1938) proposed on the basis of aircraft observations along the Southern California coast that fog formation was preceded by stratus formation at the inversion level and subsequent downward growth toward the surface of the resulting, elevated, stratus layer.

Subsequent research has not resolved the essential differences between these two original hypotheses, primarily because existing observations are not sufficient to constrain the associated distributions and processes over the full range of relevant space and time scales. The ship-based observational study of Pilié et al. (1979) partly supported the downwardgrowth interpretation, but also proposed several additional mechanisms, including fog formation triggered locally instead by instability and mixing over warm water patches. A related but more intricate mechanism for fog development along the California coast was proposed by Leipper $(1948,1994)$, initially for the southern coast during the winter season but subsequently more broadly, involving a synoptic sequence that begins with offshore advection of warm, dry, continental air that extends downward to the sea surface, and continues with local surface cooling driving the formation of a thin, strongly stable, surface layer, in which a shallow fog layer may develop from additional cooling. The recent modeling and observational case studies by Koračin et al. (2001), Lewis et al. (2003), and Koračin et al. (2005a,b) focused primarily on the downward growth mechanism, but addressed only two specific events in April 1999 and May 1997. The summary statement by Leipper (1994) that "...there remain many confusing aspects of the phenomenon such as just how fog is formed offshore... [and]. . . exactly what is the role of the sea surface temperature" is thus still valid.

Our analysis of the coupled ocean-atmosphere simulations supports the view that the primary mechanism for fog formation in the northern CCS regime is surface cooling of warm, moist, offshore air that is advected over cold, upwelled, coastal ocean waters, under synoptically controlled conditions in which the moist boundary layer air is locally capped and stabilized by a warm, dry, overlying air mass of continental origin. This view is consistent with the original hypothesis of McEwen (1912) and, in a general sense, with the idea of the role of warm continental air introduced by Leipper (1948). This mechanism is decidedly dominant in the three simulations with strictly local PBL turbulence schemes (MYNN2, GBM, and UW) but is also evident in the other three simulations.

A secondary mechanism found in the simulations is downward growth from a preexisting stratus layer, primarily on diurnal time scales. This view would be generally consistent with the alternative hypothesis described by Anderson (1931) and Petterssen (1938) and explored more recently in case studies by Koračin et al. (2001), Lewis et al. (2003), and Koračin et al. (2005a,b). 

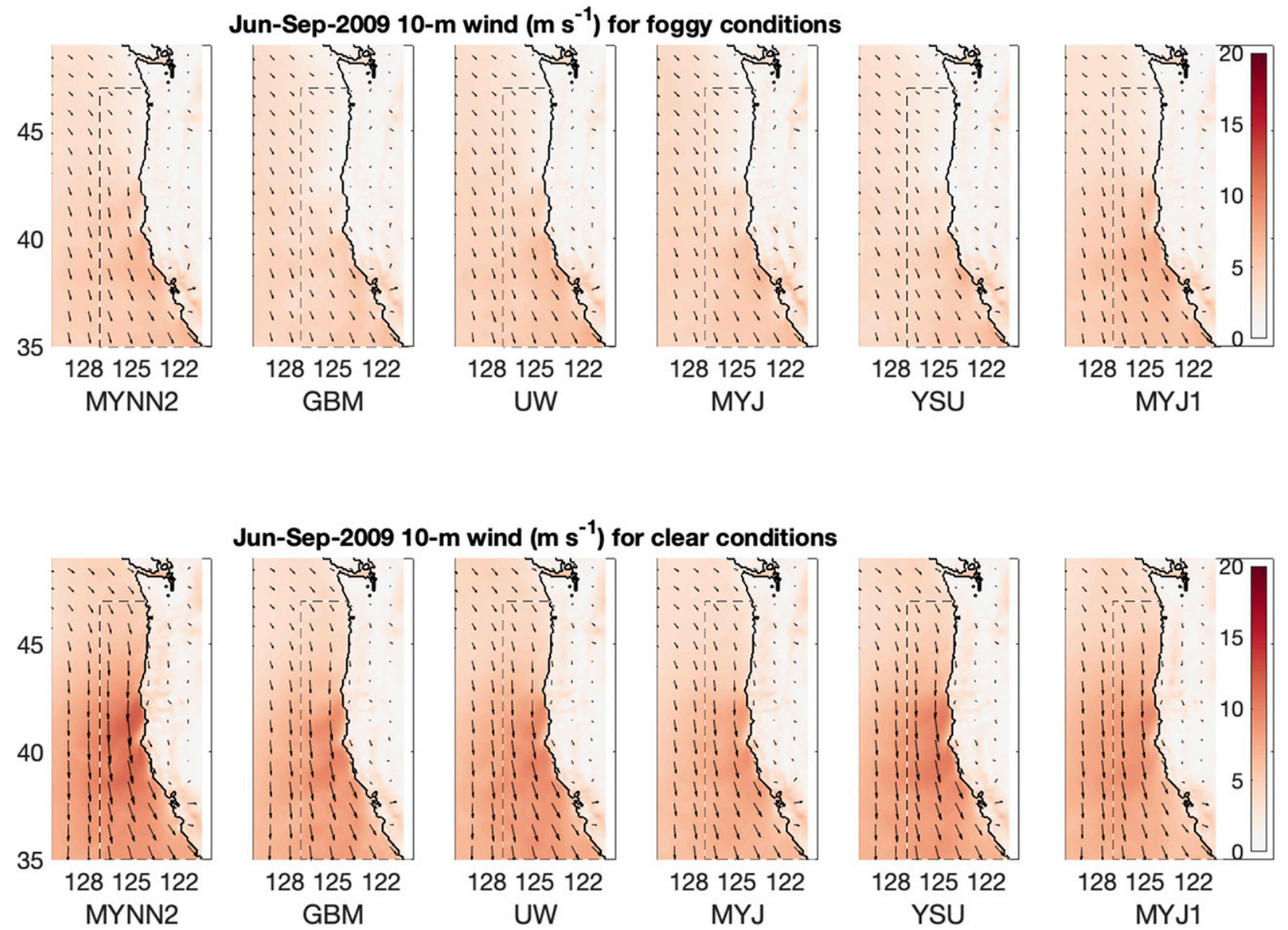

FIG. 18. Vector-mean $10 \mathrm{~m}$ wind $\left(\mathrm{m} \mathrm{s}^{-1}\right)$ from 3-hourly fields during June-September 2009 with (top) $x_{\text {vis }}<1 \mathrm{~km}$ in greater than $2.5 \times$ $10^{4} \mathrm{~km}^{2}$ (foggy conditions; see Fig. 5) in the coastal subregion and (bottom) $x_{\mathrm{vis}}<1 \mathrm{~km}$ in less than $2.5 \times 10^{4} \mathrm{~km}^{2}$ (clear conditions; see Fig. 5). Each panel is labeled by the WRF PBL scheme used in the corresponding simulation.

This mechanism is dominant in the YSU, MYJ, and MYJ1 simulations and can also occur in the simulations with strictly local PBL schemes; for example, there is a suggestion of this behavior in the region of monthly mean surface heating for the MYNN2 simulation during the first week of August (Fig. 13c). However, as discussed below (section 5c), the persistent stratus layer in the YSU, MYJ, and MYJ1 simulations that provides the primary source for this downward growth is likely at least in part an artifact, and consequently the apparent significance of this secondary mechanism is likely exaggerated by the simulations.

The importance of the stabilizing, warm, continental air for fog formation in the simulations is, as noted, generally consistent with the ideas proposed by Leipper $(1948,1994,1995)$. However, the simulations provide only partial support for the more detailed, four-phase, synoptic-mesoscale cycle that is proposed by Leipper $(1948,1994,1995)$ to be a primary driver for fog formation in this regime. The anomalously strong northeasterly winds and drying of the surface air mass identified here with clear-sky coastal-zone conditions (section $4 \mathrm{f}$ and Fig. 19) are generally similar to "Phase 1" of the Leipper (1948, 1994, 1995) conceptual model. In Leipper's "Phase 1," the offshore flow is centered farther south than in the simulations, near $38^{\circ} \mathrm{N}$ rather than $42^{\circ} \mathrm{N}$ as here, but the mechanism for initial clearing is similar, with replacement of the moist lowlevel marine air by dry continental air.

Sea fog forms adjacent to the coast as offshore flow decreases and the thermal low begins to build offshore during Leipper's "Phase 2," and then spreads northward and offshore during "Phase 3," possibly as a coastal surge (coastal trapped wind reversal). The influence of vertical confinement by warm continental air, proposed by Leipper (1948) and seen in the simulations (section 4b and Figs. 12 and 13), is critical during these phases. However, the precise nature of the local fog formation process in the layer below the stabilized inversion is not described or determined in the Leipper scenario; as noted above, Leipper (1994) regarded this as an open question. The simulations suggest that cooling-induced condensation at the surface dominates fog formation in this regime.

Further, the simulations suggest that the northern CCS system supports fog formation, growth, and extension for extended periods during which the coastal winds are dominated by northerly or northwesterly, upwelling-favorable flow. In contrast, the "Phase 2" and "Phase 3" states during which fog 

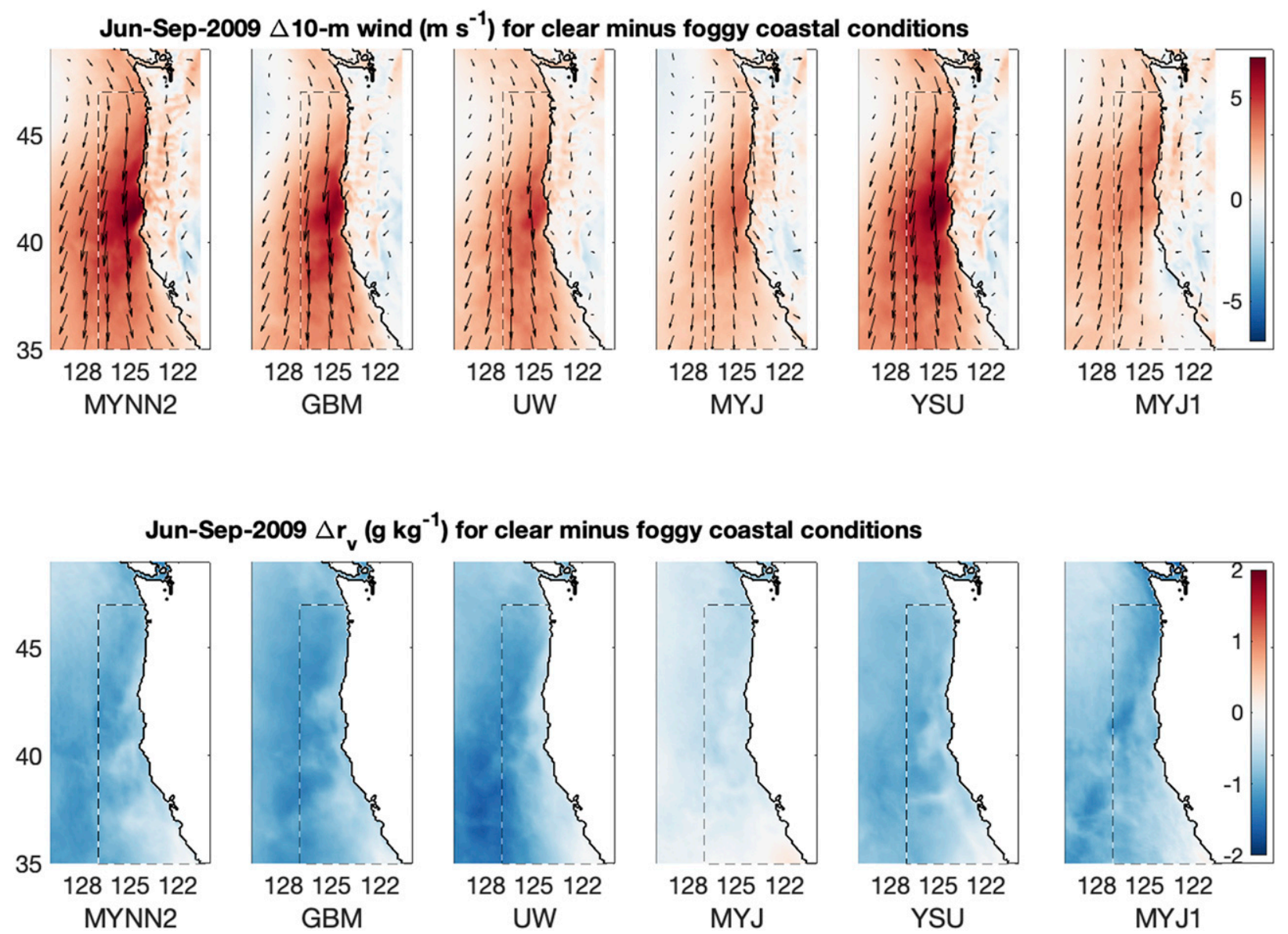

FIG. 19. Difference fields for (top) vector-mean $10 \mathrm{~m}$ wind and (bottom) mean surface water vapor $r_{v}$ (g kg ${ }^{-1}$ ) from 3-hourly fields during June-September 2009 with $x_{\mathrm{vis}}<1 \mathrm{~km}$ in less than $2.5 \times 10^{4} \mathrm{~km}^{2}$ (clear conditions; see Fig. 5) in the coastal subregion (dashed line) minus the corresponding means for $x_{\mathrm{vis}}<1 \mathrm{~km}$ in greater than $2.5 \times 10^{4} \mathrm{~km}^{2}$ (foggy conditions; see Fig. 5). The magnitude of the vectormean $10 \mathrm{~m}$ wind differences (shading and relative vector lengths) and the difference vectors (arrows) are shown. Each panel is labeled by the WRF PBL scheme used in the corresponding simulation.

prevails in the Leipper scenario are relatively calm periods, with the transition to the "Phase 4" stratus-dominated state occurring as soon as the northerly winds return. While the upwelling winds in the simulations are stronger during the clear-sky conditions than during the foggy conditions (Fig. 19a), they remain northerly during foggy conditions (Fig. 18a). This is fully consistent with the original McEwen (1912) advective-cooling hypothesis but is an evident departure from the Leipper (1948, 1994, 1995) scenario, in which fog formation and growth occur primarily during interruptions of the upwelling winds.

\section{b. Airport and remote sensing observations}

A basic obstacle to progress toward understanding the West Coast fog regime, despite the long history of study, has been the difficulty of obtaining sufficient observations to quantify fog distributions and analyze their dependence on environmental parameters. Relatively long records of fog observations at airports and, previously, lighthouses (e.g., Palmer 1917) are available but only at isolated points and, as land-based observations, provide a limited view of marine conditions. Ship observations have been compiled and analyzed by Filonczuk et al. (1995) and Neiburger et al. (1961), but again provide only a coarse view of climatological conditions. These climatologies do consistently indicate late-summer maxima in fog frequencies in much of the northern CCS upwelling region (see, e.g., figures in Koračin et al. 2005a, 2014), consistent with the general seasonal response in the coupled simulations, but are not sufficient to provide definitive quantitative evaluations of the model results.

Different boundary layer mixing schemes result in significant differences in the vertical structure and spatial extent of summer marine fog among the simulations (e.g., Figs. 7 and 8). As a broad test of their applicability, we have compared the model results with cloud-base-height observations from automated ceilometers and visibility sensors at six West Coast airports (Fig. 20). Despite the difference in the threshold, the frequency of fog (cloud water mixing ratio of $10^{-4} \mathrm{~kg} \mathrm{~kg}^{-1}$ ) in the lowest model bin falls between the frequency of fog (scattering sensor visibility $<5 / 8 \mathrm{mi} ; 1 \mathrm{mi} \approx 1.6 \mathrm{~km}$ ) and 

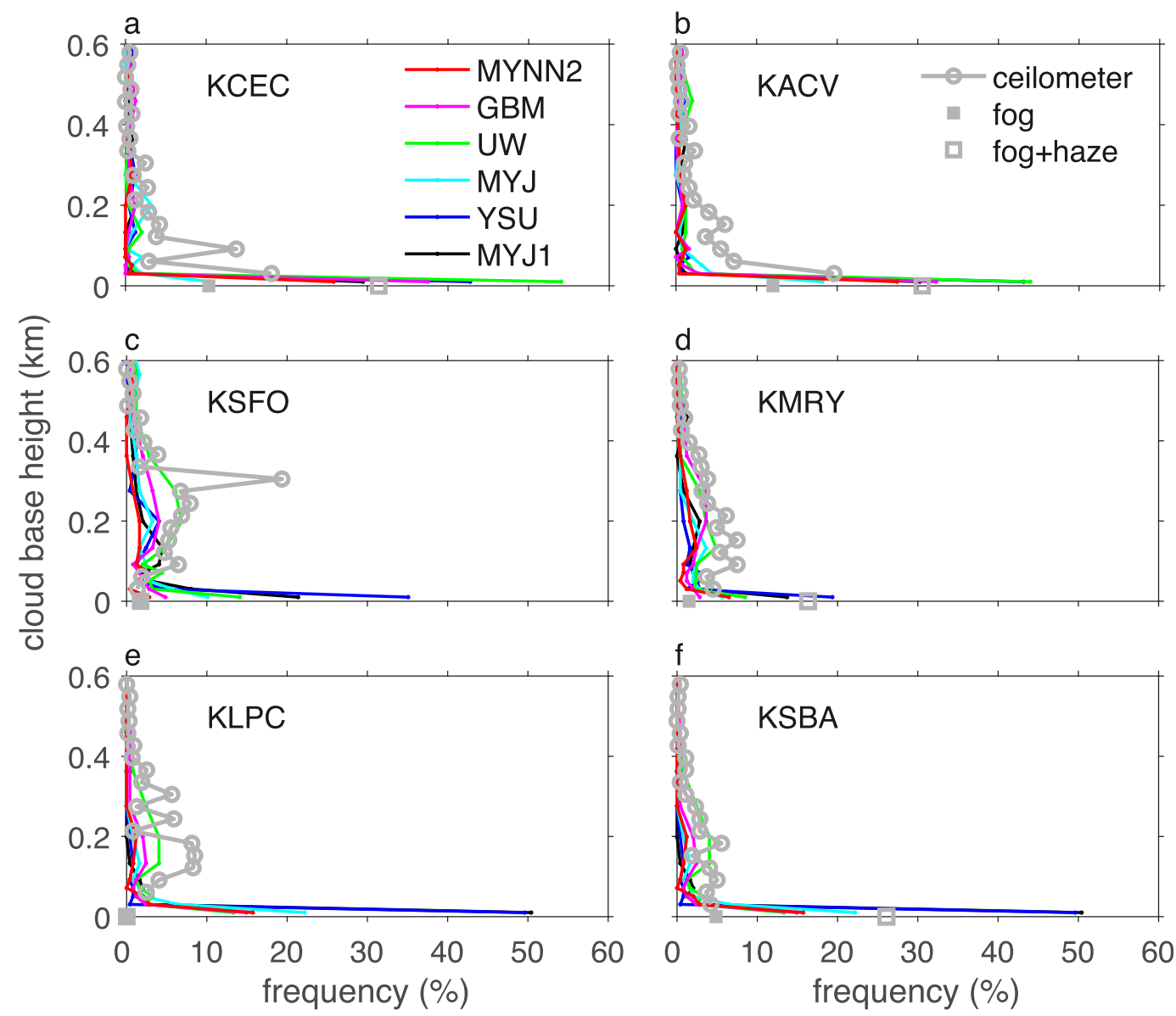

FIG. 20. August 2009 cloud-base height histograms on native model layer heights above mean sea level (MSL) for the six model simulations [color as in legend in (a)] and airport ceilometer heights above ground level (gray) at six coastal California airports: (a) Crescent City (KCEC), (b) Arcata (KACV), (c) San Francisco (KSFO), (d) Monterey (KMRY), (e) Lompoc (KLPC), and (f) Santa Barbara (KSBA). Surface observations of fog frequency (visibility $<5 / 8 \mathrm{mi}$, gray solid square) and sum of the frequency of mist and fog (visibility $<7$ mi, gray open square) from the visibility sensor. The locations, sensor site elevations (m MSL), and approximate distances from the ocean coast $(\mathrm{km})$ for those airports were, respectively, $\mathrm{KCEC}: 41.780^{\circ} \mathrm{N}, 124.236^{\circ} \mathrm{W}, 17 \mathrm{~m}, 1 \mathrm{~km}$; KACV: $40.978^{\circ} \mathrm{N}, 124.108^{\circ} \mathrm{W}, 66 \mathrm{~m}, 1 \mathrm{~km}$; KSFO: $37.619^{\circ} \mathrm{N}, 122.375^{\circ} \mathrm{W}, 3 \mathrm{~m}, 10 \mathrm{~km}$; KMRY: $36.587^{\circ} \mathrm{N}, 121.843^{\circ} \mathrm{W}, 77 \mathrm{~m}$, $3 \mathrm{~km}$; KLPC: $34.666^{\circ} \mathrm{N}, 120.468^{\circ} \mathrm{W}, 27 \mathrm{~m}, 13 \mathrm{~km}$; and KSBA: $34.426^{\circ} \mathrm{N}, 119.841^{\circ} \mathrm{W}, 3 \mathrm{~m}, 1 \mathrm{~km}$.

frequency of the sum of mist and fog (visibility $<7 \mathrm{mi}$ ) for most models at most stations. The model cloud-base-height distributions are more like each other than like the observations, so this comparison does not suggest which model experiments are more realistic. Simulated cloud bases are dominated by fog (clouds in the lowest grid point) for every model at every station in the comparison. Ground fog is commonly observed at airports, in similar to lesser amounts than in the models. There is more variability of cloud-base heights in observations than in models. Cloud bases at $100-300 \mathrm{~m}$ height as observed at airports are present in the models but are less frequent relative to fog. In central coastal California, San Francisco (KSFO), Monterey (KMRY), and Lompoc (KLPC) have more elevated cloud bases and very little fog at the surface. The models also have increased frequency of $100-300 \mathrm{~m}$ cloud bases in the central coast. The correspondence between the ceilometer observations and coupled regional model results in this comparison (Fig. 20) is much closer than that found by An et al. (2020) between West Coast ceilometer observations and reanalysis cloud-base heights and frequencies.

There are physical reasons why the models may tend to predict more fog than is observed at airports. The lower hundred meters of air of the marine fog is influenced by land heating at the airport sites, as well as laminar and turbulent effects of airflow over terrain. For safety, airports are located to optimize visibility, so they take advantage of these terrestrial effects to the detriment of fog. Many of these effects will not be represented in detail by the model because of limitations from the $12 \mathrm{~km}$ grid resolution.

A recent line of work has used satellite brightness temperatures to assess coastal low cloudiness (CLC) along the U.S. West Coast (Iacobellis and Cayan 2013; Schwartz et al. 2014; 


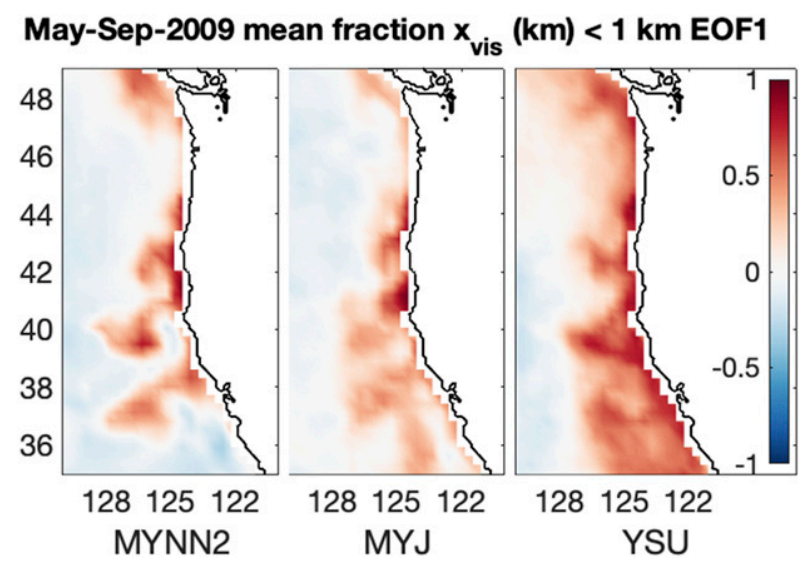

FIG. 21. EOF 1 for May-September daily mean surface lowvisibility frequency for the MYNN2, MYJ, and YSU simulations.

Clemesha et al. 2016, 2017). The satellite brightness temperature data have the advantages of broad and frequent coverage of the entire region, and much finer horizontal resolution than other previous satellite cloud observations, but are unable to distinguish fog from low clouds. For example, Clemesha et al. (2016) include all airport cloud-base heights below $2 \mathrm{~km}$ in the verification of their CLC product that is described in their supporting material. Some of this work including the recent extension to the Pacific Northwest by Dye et al. (2020) shows evidence for a marine coastal-zone mode of low-cloud variability that would be generally consistent with enhanced low clouds over cool upwelled SST, as found in the coupled simulations. For comparison with the EOFs computed from 22 years of monthly mean May-September satellite low-cloud by Dye et al. (2020), EOFs of the monthly mean frequency of surface $x_{\text {vis }}<1 \mathrm{~km}$ at each grid point were computed for each simulation for the months of May-September. Although the model time series cover only 2009 and the measures of cloudiness are different, the leading EOFs from this analysis (Fig. 21) show a distinct similarity to the second, "coastal" EOF found by Dye et al. (2020), with a wedge-shaped region of variance adjacent to the coast that broadens southward from $45^{\circ} \mathrm{N}$ to extend past $126^{\circ} \mathrm{W}$ at $42^{\circ} \mathrm{N}$. The leading EOF found by Dye et al. (2020) is a much broader, maritime mode that likely represents the larger-scale elevated low-level stratus layer rather than surface visibility, which is a more refined measure of fog. The correspondence between the Dye et al. (2020) coastal mode and the low-surface-visibility EOFs derived from the simulations suggests - but does not prove - that the satellite CLC signal for this mode likely does, at least in part, represent fog.

\section{c. PBL schemes}

A large-scale, climatological feature of eastern boundary regimes that was identified by Neiburger et al. (1961) and other subsequent studies is the offshore increase in the depth of the stratus-topped marine PBL, from a few hundred meters or less adjacent to the coast to roughly a kilometer over the open ocean. This general structure is at least partially reproduced by all of the coupled simulations (e.g., Fig. 8), despite the differences in PBL schemes, consistent with it being controlled by thermodynamic constraints that are relatively insensitive to the finer details of stability-dependent turbulent transport. However, three of the simulations (MYJ, YSU, and MYJ1) have systematically weaker stratus at the PBL top, and also produce a stronger, persistent stratus layer at a constant, much shallower height near $200 \mathrm{~m}$, independent of offshore distance (Figs. 8 and 10). There appears to be little or no observational evidence for such a persistent stratus layer extending $500 \mathrm{~km}$ offshore at a fixed $200 \mathrm{~m}$ height across the entire northern CCS. The trapping of model surface moisture in this shallow layer also appears to limit stratus formation near the top of the deeper PBL in the MYJ, YSU, and MYJ1 simulations, causing a further departure of the simulated cloud structure in these simulations from the expected climatological structure for eastern boundary regimes.

It appears highly likely, then, that this persistent, shallow stratus layer in the MYJ, YSU, and MYJ1 simulations is at least in part an artifact of the model representation and should not be interpreted as a consistently meaningful, physical feature. This conclusion is important because it is this stratus layer that is the primary source in these simulations for fog formation by the downward-growth mechanism. It therefore follows directly from this conclusion that the apparent significance of the downward growth mechanism suggested by these simulations is very likely exaggerated. Fog formation by downward growth does occur in the three simulations that do not show the persistent, shallow stratus layer, but it is much less frequent and is not the dominant formation process.

The occurrence of the persistent, shallow stratus layer in these simulations is evidently attributable to the use of an internally diagnosed PBL height variable to set mixing coefficients in the YSU and MYJ schemes but not in the MYNN2, GBM, and UW schemes. In the YSU and MYJ schemes, a diagnosed PBL height is computed internally from the profiles of bulk variables at each horizontal point and then used to determine the profile of mixing coefficients. The height of the top of the persistent, offshore, lowlevel stratus layer in the MYJ, YSU, and MYJ1 simulations is well predicted in each case by this internally diagnosed PBL height (Fig. 8, dashed lines). No such diagnosed PBL height is used by the purely local MYNN2, GBM, and UW PBL schemes, and no persistent, shallow stratus layer forms in those simulations.

For YSU (Hong et al. 2006), which is an extension of the nonlocal diffusivity model of Troen and Mahrt (1986), the eddy diffusivity and viscosity coefficients have a prescribed vertical structure that depends only on height relative to the internally diagnosed PBL height; above this point, they are set to smaller, free-atmosphere values derived from observations, following Kim and Mahrt (1992). Consequently, for YSU, the diagnosed PBL height is fundamental to the structure and extent of the PBL-scheme vertical mixing.

The role of a diagnosed PBL height in the MYJ scheme is less central to the basic design of the parameterization than for YSU but is nonetheless evidently substantial. The MYJ scheme is based on the same local "Mellor-Yamada" 
(Mellor and Yamada 1982) turbulence closure scheme as the MYNN2, GBM, and UW schemes, and the standard description of the MYJ scheme by Janjić (1994) does not mention a diagnosed PBL height. However, the version of the MYJ scheme that is implemented in WRF v3.9.1 and used in these simulations does incorporate a diagnostic PBL height (Janjić 2001). According to this prescription, the MYJ PBL height is defined as the lowest level above the surface at which the modeled turbulent kinetic energy is greater than a prescribed threshold. Above this height, the turbulent mixing-length parameter is set to its smaller, free-atmosphere value (a constant fraction of the model local vertical grid-spacing distance; Janjić 2001). The effective dependence of the MYJ turbulent kinetic energy on bulk variables is apparently similar enough to the quantities derived directly from bulk variables in YSU that the two different methods give nearly identical estimates of the PBL height in these simulations (Fig. 8).

In this context, it should also be noted that grid-limited resolution of radiative divergences at the top of the stratus layer could, in principle, result in a competing tendency of such models to underestimate the importance of the downwardgrowth process. However, the considerations above strongly suggest that the downward growth mechanism for fog formation that dominates the MYJ, YSU, and MYJ1 simulations depends on a demonstrably artificial feature of the simulations, and that its dominance in those simulations is therefore very likely an artifact.

\section{Summary}

The analysis described here has focused on identifying the dominant physical processes that control fog and low-level stratus during the coastal upwelling season in a suite of coupled ocean-atmosphere simulations of the northern California Current System. These simulations were conducted with a coupled ocean-atmosphere model that has a long heritage of development and validation against observations, but for which the fog and low-level stratus response had not previously been studied. The primary mechanism for fog formation suggested by the model simulations is condensation at the surface in response to surface cooling over cool upwelled coastal waters of warm, moist air advected into the coastal zone, under conditions in which the offshore extension of warm continental enhances the stability of the inversion at the top of the marine atmospheric boundary layer.

This suggestion is consistent with the early hypothesis of McEwen (1912), supplemented by the Leipper (1948) hypothesis for the importance of the stabilizing continental air mass. Despite the latter correspondence, however, the model does not consistently show the full, four-phase synopticmesoscale cycle of fog formation and dissipation envisioned by Leipper (1948, 1994). Fog is generally formed and subsequently maintained in the model during persistent northwesterly winds, rather than during interruptions of those winds as in the Leipper $(1948,1994)$ scenario. The analysis also suggests that the main potential alternative to the McEwen (1912) mechanism, the downward growth toward the surface from a preformed stratus layer at a shallow inversion originally proposed by Anderson (1931) and Petterssen (1938), is evidently not dominant. Formation by downward growth does occur in the simulations, but it is the dominant mechanism only in simulations that also produce an artificial, extensive, persistent, stratus layer at $200 \mathrm{~m}$ height that serves as the main source for the downward growth.

For the general problem of coastal low clouds, further analysis of remote sensing products in combination with model studies will likely lead to improved understanding. Preliminary computations that we have conducted of joint EOFs of the Clemesha et al. (2016) CLC and reanalysis 850-hPa potential temperature, and of analogous pairs of model fields, showed consistent, highly significant leading modes, with the correlations likely arising physically through modulation of northwesterly onshore flow (as in Figs. 18 and 19) but possibly also influenced by the Leipper (1948) stabilization mechanism. For the fog problem, however, existing observations do not constrain the distributions and formation processes in this region over the range of relevant space and time scales that would be required to make a definitive statement regarding the degree to which the model responses correctly reproduce the physical processes controlling fog formation in the summertime northern California Current System.

The results therefore point toward a need for additional, sustained measurements to resolve these questions. Frequent, repeated profiling of cloud liquid water, water vapor or dewpoint temperature, winds, potential temperature and other atmospheric variables from the surface to $850 \mathrm{hPa}$, along with sea surface temperature observations, at several locations in the coastal zone and offshore during a period of at least one month, and preferably through the entire upwelling season, would appear necessary to resolve the differences between the proposed mechanisms. The profiling should be conducted continuously throughout the observational period and with sufficient temporal resolution to resolve the diurnal cycle. This would be a major observational effort that substantially exceeds the directed field campaigns that have thus far been devoted to this problem. However, it could result in substantial improvements in forecast skill for fog in this region and other similar eastern boundary current systems, an achievement that would have significant benefits for ship and aircraft navigation safety and other human activities in the coastal zone (e.g., Koračin 2017).

This work was partly motivated by the need to improve understanding of the possible dependence of the coastal fog regime on changes in large-scale regional climate variables, because of its role in the coastal redwood ecosystem. For the particular processes that were found to control fog distributions in the simulations, some general inferences regarding the possible or likely evolution of the fog climate can be drawn. The primary components of the coastal ocean-atmosphere system that support fog formation in these simulations are the northwesterly, upwelling-favorable coastal winds, the difference in SST between the upstream offshore regions where the surface airmass moisture and temperature are set and the cool coastal-upwelling regions where condensation occurs, and the vertical confinement by offshore penetration of warm, dry continental air over the marine boundary layer inversion. It 


\section{Aug-2009 mean $p_{s f c}-p$ at $\max r_{c}(\mathrm{hPa})$ and surface sensible cooling $\left(5 \mathrm{~W} \mathrm{~m}^{-2}\right)$}
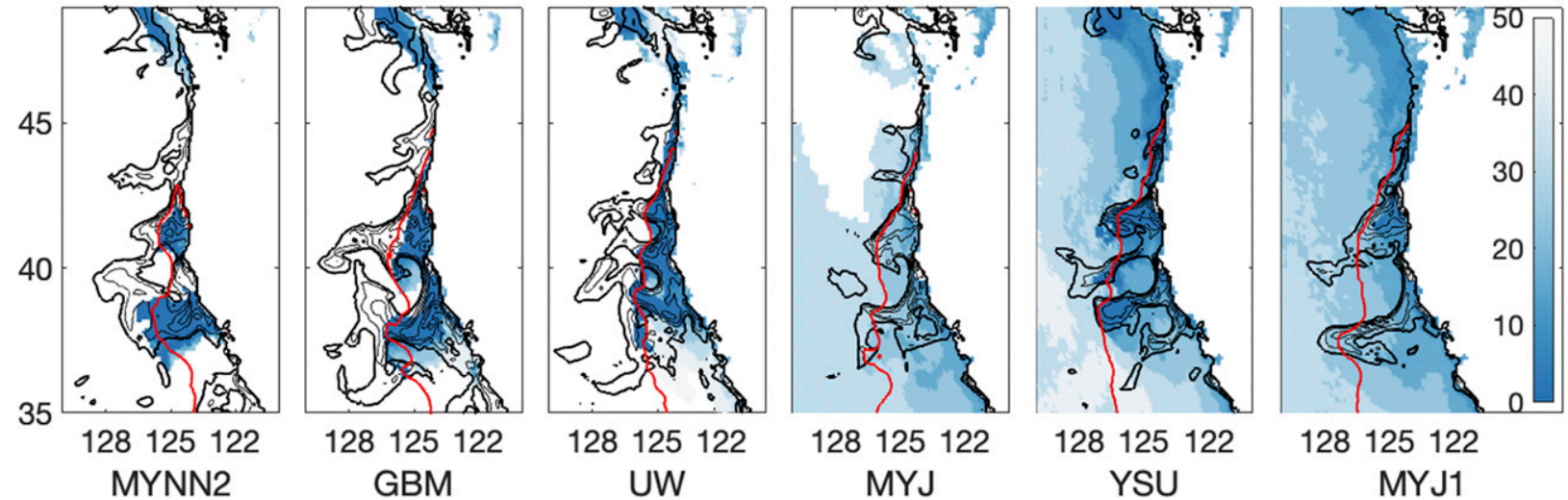

FIG. A1. As in Fig. 12, but for the original MYNN2, GBM, and YSU simulations analyzed by Samelson et al. (2020).

seems likely that the upwelling winds, offshore SSTs, and continental airmass temperatures are likely only to increase with a warming climate, so that these components would likely remain largely unchanged or possibly even intensify. This would leave the temperature of the upwelled water as the main determining factor: as long as the coastal SSTs remain of order $10^{\circ} \mathrm{C}$ colder than the late-summer offshore SSTs, the conditions would seem favorable for continued active summer fog formation even in a warming climate. However, if the warming should continue long enough and extend deep enough to increase substantially the temperatures of the source waters for the coastal upwelling, a consequent reduction of coastal fog, and thus increase in stress on the coastal redwood ecosystem, seems likely. A complicating factor is the role of the dry continental air, which in these simulations is associated both with enhanced inversion stability and fog formation, and with clearsky conditions during periods of enhanced offshore flow. It is unclear which of these effects might be favored as continental air mass properties evolve in a warming climate. The interplay between these factors can be explored through climate model simulations such as those of O'Brien et al. (2013), which have shown skill in reproducing interannual variability in climatological observations. It is hoped that the physical mechanisms and interpretations identified and explored here will contribute to further development and improvement of model predictions of coastal fog processes on synoptic, seasonal, and climaterelated time scales.

Acknowledgments. We are grateful to the editor and three anonymous reviewers for comments that helped to improve and refine the presentation of these results. This research was supported by the National Science Foundation (NSF), NSF Grants OCE-1600109 and OCE-1853039, through subawards to Oregon State University from the University of California, Merced, and the University of California, Santa Cruz, and NSF Grant AGS-1619903; and by the National Aeronautics and Space Administration (NASA) Ocean Vector Winds Science Team, NASA Grants NNX14AM66G and 80NSSC19K0061.

\section{APPENDIX}

\section{Supplementary Material-Modeling}

In addition to the PBL physics options given in section 2a, the WRF microphysics options for these simulations were: $\mathrm{mp}$ physics $=10$ (Morrison et al. 2009, two-moment option), ra_lw_physics $=4$, ra_sw_physics $=4$, sf_surface_physics $=2$, cu_physics $=1$, sf_lake_physics $=0$, sf_urban_physics $=0$, shcu_physics $=0$. A figure showing the vertical grid is available in the appendix of Samelson et al. (2020).

The UW, MYJ, and MYJ1 simulations are the same as those analyzed by Samelson et al. (2020). The MYNN2, GBM, and YSU simulations are equivalent to those analyzed by Samelson et al. (2020) but were recomputed to allow output of radiative terms. Differences in software versions and in hardware configurations made bit-for-bit duplication of the original MYNN2, GBM, and YSU simulations impossible, and consequently differences from the originally simulated SST fields developed through instability of the coastal ocean currents (e.g., Durski and Allen 2005; Durski et al. 2007; Kim et al. 2009, 2011). The original MYNN2, GBM, and YSU simulations were subjected to the same analysis described here for the recomputed simulations and gave equivalent quantitative results, as illustrated for example by comparing Fig. 12 to Fig. A1, where the latter is equivalent to the former but computed for the original MYNN2, GBM, and YSU simulations.

\section{REFERENCES}

An, N., R. Pinker, K. Wang, E. Rogers, and Z. Zuo, 2020: Evaluation of cloud base height in the North American Regional Reanalysis using ceilometer observations. Int. J. Climatol., 40, 3161-3178, https://doi.org/10.1002/joc.6389.

Anderson, J. B., 1931: Observations from airplanes of cloud and fog conditions along the southern California coast. Mon. Wea. Rev., 59, 264-270, https://doi.org/10.1175/1520-0493(1931)59<264: OFAOCA $>2.0 . \mathrm{CO} ; 2$.

Bielli, S., P. Barbour, R. Samelson, E. Skyllingstad, and J. Wilczak, 2002: Numerical study of the diurnal cycle along the central Oregon coast during summertime northerly flow. Mon. Wea. 
Rev., 130, 992-1008, https://doi.org/10.1175/1520-0493(2002) $130<0992$ :NSOTDC $>2.0$. CO;2.

Bretherton, C. S., and S. Park, 2009: A new moist turbulence parameterization in the Community Atmosphere Model. J. Climate, 22, 3422-3448, https://doi.org/10.1175/2008JCLI2556.1.

— J. R. McCaa, and H. Grenier, 2004: A new parameterization for shallow cumulus convection and its application to marine subtropical cloud-topped boundary layers. Part I: Description and 1D results. Mon. Wea. Rev., 132, 864-882, https://doi.org/ 10.1175/1520-0493(2004)132<0864:ANPFSC >2.0.CO;2.

Byers, H. R., 1930: Summer sea fogs off the central California coast. Univ. Calif. Publ. Geogr., 3, 291-338.

Clemesha, R. E. S., A. Gershunov, S. F. Iacobellis, A. P. Williams, and D. R. Cayan, 2016: The northward march of summer low cloudiness along the California coast. Geophys. Res. Lett., 43, 1287-1295, https://doi.org/10.1002/2015GL067081.

,,--- , and D. R. Cayan, 2017: Daily variability of California coastal low cloudiness: A balancing act between stability and subsidence. Geophys. Res. Lett., 44, 3330-3338, https://doi.org/10.1002/2017GL073075.

Durski, S. M., and J. S. Allen, 2005: Finite-amplitude evolution of instabilities associated with the coastal upwelling front. J. Phys. Oceanogr., 35, 1606-1628, https://doi.org/10.1175/ JPO2762.1.

,-- , G. D. Egbert, and R. M. Samelson, 2007: Scale evolution of finite-amplitude instabilities on a coastal upwelling front. J. Phys. Oceanogr., 37, 837-854, https://doi.org/10.1175/ JPO2994.1.

—_, A. L. Kurapov, J. S. Allen, P. M. Kosro, G. D. Egbert, R. K. Shearman, and J. A. Barth, 2015: Coastal ocean variability in the US Pacific Northwest region: Seasonal patterns, winter circulation, and the influence of the 2009-2010 El Niño. Ocean Dyn., 65, 1643-1663, https://doi.org/10.1007/ s10236-015-0891-1.

Dye, A. W., B. Rastogi, R. E. Clemesha, J. B. Kim, R. M. Samelson, C. J. Still, and A. P. Williams, 2020: Spatial patterns and trends of summertime low cloudiness for the Pacific Northwest, 19962017. Geophys. Res. Lett., 47, e2020GL088121, https://doi.org/ 10.1029/2020GL088121.

Filonczuk, M. K., D. R. Cayan, and L. G. Riddle, 1995: Variability of marine fog along the California coast. Scripps Institution of Oceanography, Tech. Rep. 95-2, 91 pp.

Grenier, H., and C. S. Bretherton, 2001: A moist PBL parameterization for large-scale models and its application to subtropical cloud-topped marine boundary layers. Mon. Wea. Rev., 129, 357-377, https://doi.org/10.1175/1520-0493(2001)129<0357: AMPPFL $>2.0 . C O ; 2$.

Gultepe, I., M. D. Müller, and Z. Boybeyi, 2006: A new visibility parameterization for warm-fog applications in numerical weather prediction models. J. Appl. Meteor. Climatol., 45, 1469-1480, https://doi.org/10.1175/JAM2423.1.

Hong, S.-Y., Y. Noh, and J. Dudhia, 2006: A new vertical diffusion package with an explicit treatment of entrainment processes. Mon. Wea. Rev., 134, 2318-2341, https://doi.org/ 10.1175/MWR3199.1.

Iacobellis, S. F., and D. R. Cayan, 2013: The variability of California summertime marine stratus: Impacts on surface air temperatures. J. Geophys. Res. Atmos., 118, 9105-9122, https://doi.org/10.1002/jgrd.50652.

Janjić, Z. I., 1994: The step-mountain Eta coordinate model: Further developments of the convection, viscous sublayer, and turbulence closure schemes. Mon. Wea. Rev., 122, 927-945, https://doi.org/ 10.1175/1520-0493(1994)122<0927:TSMECM > 2.0.CO;2.
_- 2001: Nonsingular implementation of the Mellor-Yamada level 2.5 scheme in the NCEP Meso model. NCEP Office Note 437, $61 \mathrm{pp}$.

— nonhydrostatic multiscale model on the B grid (NMMB). Part 1: Dynamics. NCAR Tech. Note NCAR/TN-489+STR, 75 pp., https://doi.org/10.5065/D6WH2MZX.

Johnstone, J. A., and T. E. Dawson, 2010: Climatic context and ecological implications of summer fog decline in the coast redwood region. Proc. Natl. Acad. Sci. USA, 107, 4533-4538, https://doi.org/10.1073/pnas.0915062107.

Jones, E. L., 1918: The neglected waters of the Pacific coast: Washington, Oregon, and California. Special Publication 48, Department of Commerce, U.S. Coast and Geodetic Survey, 21 pp.

Kim, J., and L. Mahrt, 1992: Simple formulation of turbulent mixing in the stable free atmosphere and nocturnal boundary layer. Tellus, 44A, 381-394, https://doi.org/10.3402/tellusa.v44i5.14969.

Kim, S., R. M. Samelson, and C. Snyder, 2009: Ensemble-based estimates of the predictability of wind-driven coastal ocean flow over topography. Mon. Wea. Rev., 137, 2515-2537, https:// doi.org/10.1175/2009MWR2631.1.

,$- \ldots$, and — 2011: Toward an uncertainty budget for a coastal ocean model. Mon. Wea. Rev., 139, 866-884, https:// doi.org/10.1175/2010MWR3352.1.

Klein, S. A., and D. L. Hartmann, 1993: The seasonal cycle of low stratiform clouds. J. Climate, 6, 1587-1606, https://doi.org/ 10.1175/1520-0442(1993)006<1587:TSCOLS $>2.0$.CO;2.

Koračin, D., 2017: Modeling and forecasting marine fog. Marine Fog: Challenges and Advancements in Observations, Modeling, and Forecasting, D. Koračin and C. E. Dorman, Eds., Springer, 477-509.

— J. Lewis, W. T. Thompson, C. E. Dorman, and J. A. Businger, 2001: Transition of stratus into fog along the California coast: Observations and modeling. J. Atmos. Sci., 58, 1714-1731, https:// doi.org/10.1175/1520-0469(2001)058<1714:TOSIFA > 2.0.CO;2.

- J. A. Businger, C. E. Dorman, and J. M. Lewis, 2005a: Formation, evolution, and dissipation of coastal sea fog. Bound.-Layer Meteor., 117, 447-478, https://doi.org/10.1007/ s10546-005-2772-5.

— D. F. Leipper, and J. M. Lewis, 2005b: Modeling sea fog on the U.S. California coast during a hot spell event. Geofizika, 22, 59-82.

—, C. E. Dorman, J. M. Lewis, J. G. Hudson, E. M. Wilcox, and A. Torregrosa, 2014: Marine fog: A review. Atmos. Res., 143, 142-175, https://doi.org/10.1016/j.atmosres.2013.12.012.

Kunkel, B. A., 1984: Parameterization of droplet terminal velocity and extinction coefficient in fog models. J. Climate Appl. Meteor., 23, 34-41, https://doi.org/10.1175/1520-0450(1984) $023<0034:$ PODTVA $>2.0$. CO; 2 .

Kurapov, A. L., S. Y. Erofeeva, and E. Myers, 2017a: Coastal sea level variability in the U.S. West Coast Ocean Forecast System (WCOFS). Ocean Dyn., 67, 23-36, https://doi.org/10.1007/s10236016-1013-4.

— N. A. Pelland, and D. L. Rudnick, 2017b: Seasonal and interannual variability in along-slope oceanic properties off the U.S. West Coast: Inferences from a high-resolution regional model. J. Geophys. Res. Oceans, 122, 5237-5259, https:// doi.org/10.1002/2017JC012721.

Leipper, D. F., 1948: Fog development at San Diego, California. J. Mar. Res., 7, 337-346.

_- 1994: Fog on the U.S. West Coast: A review. Bull. Amer. Meteor. Soc., 75, 229-240, https://doi.org/10.1175/15200477(1994)075<0229:FOTUWC>2.0.CO;2. 
1995: Fog forecasting objectively in the California coastal area using LIBS. Wea. Forecasting, 10, 741-762, https://doi.org/ 10.1175/1520-0434(1995)010<0741:FFOITC $>2.0 . C O ; 2$.

Lewis, J., D. Koracin, R. Rabin, and J. Businger, 2003: Sea fog off the California coast: Viewed in the context of transient weather systems. J. Geophys. Res., 108, 4457, https://doi.org/ 10.1029/2002JD002833.

McEwen, G. F., 1912: The distribution of ocean temperatures along the west coast of North America deduced from Ekman's theory of the upwelling of cold water from the adjacent ocean depths. Int. Rev. Gesamten Hydrobiol. Hydrograph., 5, 243 286, https://doi.org/10.1002/iroh.19120050205.

Mellor, G., and T. Yamada, 1982: Development of a turbulence closure model for geophysical fluid problems. Rev. Astrophys. Space Phys., 20, 851-875, https://doi.org/10.1029/RG020i004p00851.

Morrison, H., G. Thompson, and V. Tatarskii, 2009: Impact of cloud microphysics on the development of trailing stratiform precipitation in a simulated squall line: Comparison of oneand two-moment schemes. Mon. Wea. Rev., 137, 991-1007, https://doi.org/10.1175/2008MWR2556.1.

Nakanishi, M., and H. Niino, 2004: An improved Mellor-Yamada level-3 model with condensation physics: Its design and verification. Bound.-Layer Meteor., 112, 1-31, https://doi.org/ 10.1023/B:BOUN.0000020164.04146.98.

— and - 2006: An improved Mellor-Yamada level-3 model: Its numerical stability and application to a regional prediction of advection fog. Bound.-Layer Meteor., 119, 397-407, https:// doi.org/10.1007/s10546-005-9030-8.

— , and - 2009: Development of an improved turbulence closure model for the atmospheric boundary layer. J. Meteor. Soc. Japan, 87, 895-912, https://doi.org/10.2151/jmsj.87.895.

Neiburger, M., D. S. Johnson, and C. W. Chien, 1961: Studies of the Structure of the Atmosphere over the Eastern Pacific Ocean in Summer. University of California Press, 94 pp.

O'Brien, T. A., L. C. Sloan, P. Y. Chuang, I. C. Faloona, and J. A. Johnstone, 2013: Multidecadal simulation of coastal fog with a regional climate model. Climate Dyn., 40, 2801-2812, https:// doi.org/10.1007/s00382-012-1486-x.

Oke, P. R., and Coauthors, 2002: A modeling study of the threedimensional continental shelf circulation off Oregon. Part I: Model-data comparisons. J. Phys. Oceanogr., 32, 1360-1382, https://doi.org/10.1175/1520-0485(2002)032<1360:AMSOTT> 2.0.CO;2.

Olson, J. B., J. S. Kenyon, W. A. Angevine, J. M. Brown, M. Pagowski, and K. Sušelj, 2019: A description of the MYNN-EDMF scheme and the coupling to other components in WRF-ARW. Earth System Research Laboratory, Tech. Rep. GSD-61, 42 pp.

Palmer, A. H., 1917: Fog along the California coast. Mon. Wea. Rev., 45, 496-499, https://doi.org/10.1175/1520-0493(1917) 45<496:FATCC $>2.0 . \mathrm{CO} ; 2$.

Perlin, N., R. M. Samelson, and D. B. Chelton, 2004: Scatterometer and model wind and wind stress in the Oregon-northern California coastal zone. Mon. Wea. Rev., 132, 2110-2129, https://doi.org/ 10.1175/1520-0493(2004)132<2110:SAMWAW>2.0.CO;2.
- S. P. de Szoeke, D. B. Chelton, R. M. Samelson, E. D. Skyllingstad, and L. W. O'Neill, 2014: Modeling the atmospheric boundary layer wind response to mesoscale sea surface temperature perturbations. Mon. Wea. Rev., 142, 4284-4307, https://doi.org/10.1175/MWR-D-13-00332.1.

Petterssen, S., 1938: On the causes and the forecasting of the California fog. Bull. Amer. Meteor. Soc., 19, 49-55, https:// doi.org/10.1175/1520-0477-19.2.49.

Pilié, R. J., E. J. Mack, C. W. Rogers, U. Katz, and W. C. Kocmond, 1979: The formation of marine fog and the development of fog-stratus systems along the California coast. J. Appl. Meteor., 18, 1275-1286, https://doi.org/ 10.1175/1520-0450(1979)018<1275:TFOMFA > 2.0.CO;2.

Samelson, R., and Coauthors, 2002: Wind stress forcing of the Oregon coastal ocean during the 1999 upwelling season. J. Geophys. Res., 107, 3034, https://doi.org/10.1029/2001JC000900.

L. W. O'Neill, D. B. Chelton, E. D. Skyllingstad, P. L. Barbour, and S. M. Durski, 2020: Surface stress and atmospheric boundary layer response to mesoscale SST structure in coupled simulations of the northern California Current System. Mon. Wea. Rev., 148, 259-287, https://doi.org/ 10.1175/MWR-D-19-0200.1.

Schwartz, R. E., A. Gershunov, S. F. Iacobellis, and D. R. Cayan, 2014: North American west coast summer low cloudiness: Broadscale variability associated with sea surface temperature. Geophys. Res. Lett., 41, 3307-3314, https://doi.org/ 10.1002/2014GL059825.

Shchepetkin, A. F., and J. C. McWilliams, 2005: The Regional Ocean Modeling System (ROMS): A split-explicit, free-surface, topography-following-coordinate ocean model. Ocean Modell., 9, 347-404, https://doi.org/10.1016/j.ocemod.2004.08.002.

Simon, R. L., 1977: The summertime stratus over the offshore waters of California. Mon. Wea. Rev., 105, 1310-1314, https://doi.org/ 10.1175/1520-0493(1977)105<1310:TSSOTO>2.0.CO;2.

Skamarock, W. C., and Coauthors, 2008: A description of the Advanced Research WRF version 3. NCAR Tech. Note NCAR/ TN-468+STR, 113 pp., https://doi.org/10.5065/D68S4MVH.

Springer, S. R., R. M. Samelson, J. S. Allen, G. D. Egbert, A. L. Kurapov, R. N. Miller, and J. C. Kindle, 2009: A nested grid model of the Oregon coastal transition zone: Simulations and comparisons with observations during the 2001 upwelling season. J. Geophys. Res., 114, C02010, https://doi.org/10.1029/ 2008JC004863.

Stoelinga, M. T., and T. T. Warner, 1999: Nonhydrostatic, mesobeta-scale model simulations of cloud ceiling and visibility for an East Coast winter precipitation event. J. Appl. Meteor., 38, 385-404, https://doi.org/10.1175/15200450(1999)038<0385:NMSMSO > 2.0.CO;2.

Troen, I., and L. Mahrt, 1986: A simple model of the atmospheric boundary layer sensitivity to surface evaporation. Bound.-Layer Meteor., 37, 129-148, https://doi.org/10.1007/ BF00122760.

Warner, J. C., B. Armstrong, R. He, and J. B. Zambon, 2010: Development of a Coupled Ocean-Atmosphere-Wave-Sediment Transport (COAWST) modeling system. Ocean Modell., 35, 230244, https://doi.org/10.1016/j.ocemod.2010.07.010. 